\title{
Leptin secreted from testicular microenvironment modulates hedgehog signaling to augment the endogenous function of Leydig cells
}

\author{
Himanshu Arora (iD ${ }^{1,2,3}{ }^{凶}$, Rehana Qureshi ${ }^{3}$, Kajal Khodamoradi $^{1}$, Deepa Seetharam ${ }^{1}$, Madhumita Parmar ${ }^{1}$, Derek J. Van Booven ${ }^{3}$, \\ Isabelle Catherine Issa ${ }^{1}$, Robert Sackstein ${ }^{4}$, Dolores Lamb ${ }^{5}$, Joshua M. Hare $\mathbb{D}^{2,6}$ and Ranjith Ramasamy ${ }^{1,2}$
}

(c) The Author(s) 2022

\begin{abstract}
Although testosterone deficiency (TD) may be present in one out of five men 40 years or older, the factors responsible for TD remain largely unknown. Leydig stem cells (LSCS) differentiate into adult Leydig cells (ALC) and produce testosterone in the testes under the pulsatile control of luteinizing hormone (LH) from the pituitary gland. However, recent studies have suggested that the testicular microenvironment (TME), which is comprised of Sertoli and peritubular myoid cells (PMC), plays an instrumental role in LSC differentiation and testosterone production under the regulation of the desert hedgehog signaling pathway (DHH). It was hypothesized that the TME releases paracrine factors to modulate LSC differentiation. For this purpose, cells (Sertoli, PMCs, LSCs, and ALCs) were extracted from men undergoing testis biopsies for sperm retrieval and were evaluated for the paracrine factors in the presence or absence of the TME (Sertoli and PMC). The results demonstrated that TME secretes leptin, which induces LSC differentiation and increases testosterone production. Leptin's effects on LSC differentiation and testosterone production, however, are inversely concentration-dependent: positive at low doses and negative at higher doses. Mechanistically, leptin binds to the leptin receptor on LSCs and induces DHH signaling to modulate LSC differentiation. Leptin-DHH regulation functions unidirectionally insofar as DHH gain or loss of function has no effect on leptin levels. Taken together, these findings identify leptin as a key paracrine factor released by cells within the TME that modulates LSC differentiation and testosterone release from mature Leydig cells, a finding with important clinical implications for TD.
\end{abstract}

Cell Death and Disease (2022)13:208; https://doi.org/10.1038/s41419-022-04658-3

\section{INTRODUCTION}

Male hypogonadism is a symptomatic clinical syndrome caused by testosterone deficiency (TD) [1]. In the European Male Ageing Study, $17.0 \%$ of men aged $40-79$ years had serum testosterone levels below normal values, indicating a high prevalence of hypogonadism among middle-aged and elderly males [2]. The current standard of the cure for men with TD is lifelong exogenous testosterone therapy [3]. However, continuous exogenous testosterone supplementation negatively affects the hypothalamicpituitary-gonadal (HPG) axis, inhibiting follicle-stimulating hormone $(\mathrm{FSH})$ and luteinizing hormone $(\mathrm{LH})$ production, resulting in infertility [3-8]. Consequently, there is a need to study ways to increase serum testosterone while simultaneously preserving the HPG axis and fertility.

The testis is comprised of Leydig cells, Sertoli cells, peritubular myoid cells, and germ cells. Together these cell types perform two important functions-spermatogenesis and testosterone production [9-12]. Leydig cells are among the interstitial cells which produce testosterone under the pulsatile control of the pituitary luteinizing hormone (LH) $[13,14]$. We showed that in the absence of Sertoli and PMCs (which together constitute the testicular microenvironment (TME)), the function and rate of differentiation of Leydig stem cells (LSCs) is severely impaired [15]. This observation has also been supported by independent studies [16], suggesting that cells within the TME release paracrine factors that are critical for stimulating the differentiation of LSCs $[15,16]$.

In the present study, using cells dispersed from human testicular biopsies, we found that leptin is a paracrine factor secreted by the TME that is instrumental in regulating LSC function and differentiation to ALCs. The molecular events behind leptin-mediated regulation were defined to be through the desert hedgehog signaling pathway $\left(\mathrm{DHH}_{1}\right)$ which is downstream of leptin. DHH signaling is closely linked to developmental processes, tissue and stem cell maintenance [17-21], and modulates LSC differentiation and testosterone production under physiological conditions $[15,16]$. Considering these findings, this study unveils paracrine factors critical for LSC function and differentiation,

\footnotetext{
${ }^{1}$ Department of Urology, Miller School of Medicine, University of Miami, Miami, FL, USA. ${ }^{2}$ The Interdisciplinary Stem Cell Institute, Miller School of Medicine, University of Miami, Miami, FL, USA. ${ }^{3}$ John P Hussman Institute for Human Genomics, Miller School of Medicine, University of Miami, Miami, FL, USA. ${ }^{4}$ Herbert Wertheim College of Medicine, Florida

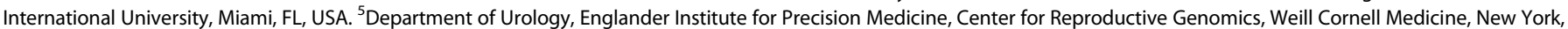
NY, USA. ${ }^{6}$ Department of Medicine, Cardiology Division, Miller School of Medicine, University of Miami, Miami, FL, USA. ${ }^{\circ}$ email: Hxa287@miami.edu Edited by Dr Yufang Shi
} 
providing new approaches for optimizing patient outcomes for men with testosterone deficiency.

\section{RESULTS \\ Isolation and characterization of testicular cells from human testis biopsies}

Individual cell constituents were isolated from testis biopsies from men undergoing sperm retrieval $(n=18$; Table 1$)$. After cells were stabilized in culture, flow cytometry and immunostaining were performed to characterize the cell types for the presence of LSCs (PDGFRa and Nestin), ALCs (B3HSD and HSD17B3), Sertoli cells (SOX9, Vimentin), PMCs (SMHC and alpha SMA), and germ cells (PLZF, DDX4 (VASA)) (Fig. 1A, B). It is known that under normal physiological conditions, stimulation with $\mathrm{LH}$ modulates the testosterone secretion from Leydig cells [22]. To recapitulate the scenario in vitro, we treated the cells with HCG and evaluated the expression of B3HSD and PDGFRa. Results showed that upon stimulation with $\mathrm{LH}$, the expression of B3HSD was increased and that of PDGFRa was decreased compared to unstimulated cells (Fig. 1C). Furthermore, we studied the architecture of the TME in 5 random testis biopsies with variable FSH and testosterone levels to confirm if variabilities in hormone levels could confound the TME. Results showed that the TME remained intact in all these patients (Sup Fig. 1A). Together, the data suggest that individual components of human testis could be successfully isolated, cultured, and differentiated in in vitro conditions.

\section{DHH is essential for the differentiation of human Leydig stem cells}

To test whether $\mathrm{DHH}$ is important for differentiation of human LSCs, testosterone levels were compared in conditioned media extracted from the cellular composition (LSCs, ALCs, PMCs, and Sertoli cells) following treatment with either DHH agonist (SAG) or antagonist (Vismodigib). Testosterone levels were increased by $24.7 \%$ upon SAG $(69.05 \pm 3.00 \mathrm{ng} / \mathrm{dL})(p=0.039)$ and minimally (nonsignificantly) reduced by $3.2 \%$ upon Vismodigib treatment $(53.52 \pm 2.59 \mathrm{ng} / \mathrm{dL})(p=0.907)$ compared to untreated samples $(55.31 \pm 3.28 \mathrm{ng} / \mathrm{dL}$ ) (Sup Fig. 1B). Furthermore, the expression of GLI, SMO (DHH markers), and B3HSD was compared in LSCs $\left(C D 146^{+v e}\right.$-sorted cells) in the presence or absence of the TME (Sertoli and PMCs). CD146 is a perivascular pericyte marker, which expresses in Nestin-positive LSCs and other multipotent progenitor cells [23]. Results showed a $41.8 \%$ reduction in GLI $(p=0.024)$, a $73.5 \%$ reduction in SMO $(p=0.025)$, and a $81.4 \%$ reduction in B3HSD $(p=0.0019)$ expression in CD146 ${ }^{+v}$ cells compared to LSCs in the presence of the TME (Fig. 2A). Moreover, when LSCs were treated with Vismodigib, in the presence of the TME for 48, 72 , and $96 \mathrm{~h}$, the expression of GLI was reduced by $36.7 \%$ ( $p=$ $0.046)$, SMO by $90.76 \%(p=0.0003)$, and B3HSD by $82.14 \%(p<$ 0.0073 ) after $96 \mathrm{~h}$ of treatment. Conversely, upon SAG treatment, the expression of GLI was increased by $2962 \%(p=0.0009)$, SMO by $204 \%(p=0.148)$, and B3HSD by $532.5 \%(p=0.0351)$ after $96 \mathrm{~h}$ of treatment (Fig. 2B). Interestingly, comparing the expression of $\mathrm{GLI}, \mathrm{SMO}$, and B3HSD in CD146 ${ }^{\mathrm{v} \text { e }}$ in the presence or absence of the TME after DHH agonist treatment showed that the extent of the increase in the expression of GLI was reduced by $152.4 \%$ ( $p=$ $0.049)$, of SMO by $74.8 \%(p<0.0001)$, and of B3HSD nonsignificantly by $7.5 \%(p=0.472)$ in $\mathrm{CD} 146^{+\mathrm{ve}}$ cells (Fig. $\left.2 \mathrm{C}, \mathrm{D}\right)$. To further validate the importance of DHH signaling on human LSC differentiation, the $\mathrm{CD} 146^{+}$cells were treated with SAG, and the expression of stem cell markers-Oct4, NANOG, PDGFRA, COUPTF11, CD51, and CD90 was evaluated $48 \mathrm{~h}$ posttreatment. A significant decrease was observed in the expression of Oct4 ( $p=$ $0.02)$, NANOG $(p=0.04)$, CD90 $(p=0.005)$, COUP-TF11 $(p=0.04)$, and SOX4 $(p=0.03)$ (Sup Fig. 2), suggesting transformation of LSCs to ALCs in the presence of $\mathrm{DHH}$ agonist. Together, the results delineated that $\mathrm{DHH}$ signaling is important for human LSCs
(HLSCs)-modulated testosterone levels and, in the absence of the $\mathrm{TME}$, the impact of DHH signaling is reduced. These outcomes led us to hypothesize that the TME releases paracrine factors that are important in modulating DHH signaling-induced LSC differentiation and testosterone production.

\section{Paracrine factors released by the TME support LSC function} To identify factors released by the TME, a cytokine antibody array was performed using conditioned media from LSCs in the absence $\left(C D 146^{+v e}\right.$ cells) or presence of the TME (Fig. 2D). Among 80 screened cytokines, leptin was identified as one whose expression was significantly decreased $(p=0.026)$ in the absence of TME(Fig. $2 \mathrm{E}$ and Sup Fig. 3). In the cellular composition, we confirmed that leptin is expressed in LSCs, ALCs, and Sertoli cells, and the leptin receptors are expressed in Leydig cells (both LSCs and ALCs) (Sup Fig. 4A, B). Next, to evaluate the effects of leptin in conjunction with DHH signaling on LSC differentiation, the cellular composition was treated with varying doses of leptin ranging from 0 to $1000 \mathrm{ng} / \mathrm{ml}$. Interestingly, lower concentrations (up to $2 \mathrm{ng} / \mathrm{ml}$ ) of leptin increased the expression of markers of $\mathrm{DHH}$ signaling $122.7 \%$ for SMO $(p=0.045)$ and a nonsignificant increment of $27.6 \%$ for GLI ( $p=0.452)$ and of the LSC differentiation marker (364.7\% for B3HSD $(p=0.003))$; however, these effects diminished with increasing leptin concentrations (from $10-1000 \mathrm{ng} / \mathrm{ml}$ ) such that at $1000 \mathrm{ng} / \mathrm{ml}$ there was a nonsignificant $13.3 \%$ decrease in the expression of SMO $(p=0.712)$, a $36 \%$ decrease in GLI $(p=0.342)$, and a $48 \%$ increase in B3HSD ( $p=$ 0.388) compared to untreated cells (Fig. $3 \mathrm{~A}$ and Sup Fig. 4C). Additionally, low dose leptin treatment increased the number of cells staining positive for alpha SMA by $253.7 \%(p=0.01)$, SMHC by $674.3 \%(p<0.0001)$, Vimentin for $298.5 \%(p<0.0001)$, B3HSD by $130.1 \%(p=0.034)$, SMO by $110 \%(p=0.032)$, and SOX9 by $184 \%(p=0.006)$ (Fig. 3B). This further suggested that leptin receptors are present in different cell types in the testis. Moreover, the question of whether leptin affects cell proliferation of LSCs was determined by treating the LSCs with varying concentrations of leptin ranging from $2,10,25,50,100,250$, and $500 \mathrm{ng} / \mathrm{ml}$. Results showed suppressive $(p>0.05)$ or no effects of leptin on LSC cell proliferation (Fig. $3 C$ ). Together, the results delineated that leptin is a potent paracrine factor secreted by the TME and could induce LSC differentiation.

One important concern was if the processing of a testis biopsy and expansion of cells in culture could confound the leptin. To address this, a testis biopsy from a healthy fertile man was obtained and the protein was extracted from half of the piece within $4 \mathrm{~h}$ of its arrival. The remaining half was used to extract the cells [15]. Once the cells were stably cultured, the conditioned media was isolated; Aditionally in addition, the protein was extracted from the cells. Protein from two sources (biopsy and cells) and conditioned media were compared for paracrine factors. Results delineated that the leptin levels remained similar in all the conditions, whereas differences were observed for markers such as TIMP-2, TIMP-1, TGFB2, NT-3, MIF, IGFBP-2, MCP-1, IL-8, and IL-6 respectively (Sup Fig. 5). Together these results suggested that processing and cell isolation does not influence leptin.

\section{Leptin is upstream of DHH signaling in the TME}

Next, to study if the effects of leptin on DHH signaling are unidirectional or bidirectional, a cytokine antibody array was performed using condition media from LSCs treated with $\mathrm{DHH}$ agonist (SAG) or antagonist (Vismodigib) (Fig. 4A). No effects on the overall leptin levels were observed upon $\mathrm{DHH}$ signaling inhibition or induction (with a $1.6 \%$ increase in leptin upon $\mathrm{DHH}$ inhibition and a $2.4 \%$ increase with $\mathrm{DHH}$ induction) (Fig. 4B, C). However, as shown in Sup Fig. 1B, DHH agonist (SAG) and antagonist (Vismodigib) have direct impacts on testosterone levels (testosterone levels increased by $24.7 \%$ upon SAG and reduced by $3.2 \%$ upon Vismodigib treatment compared to untreated 


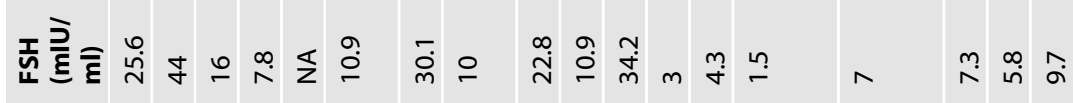

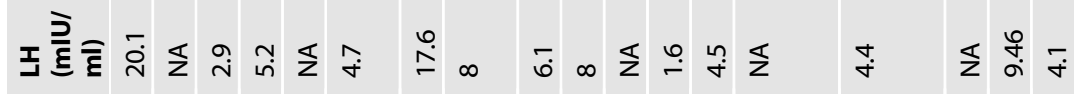

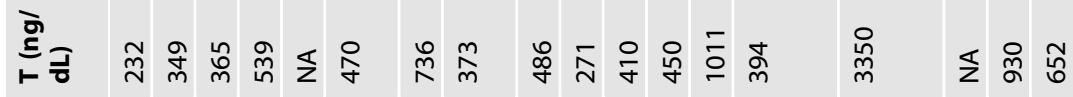

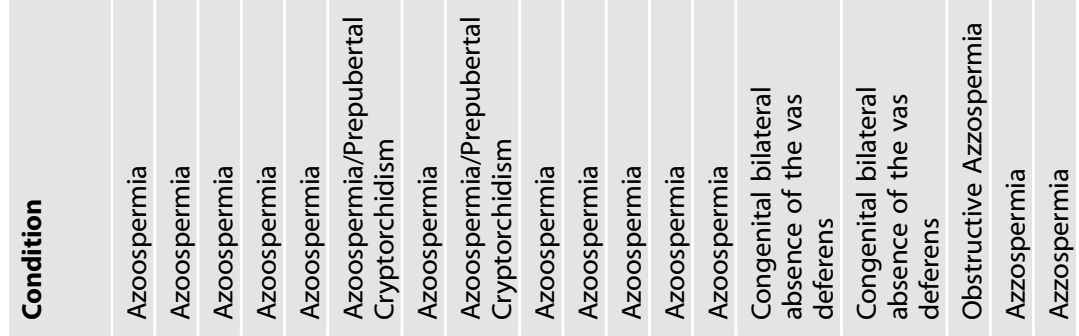

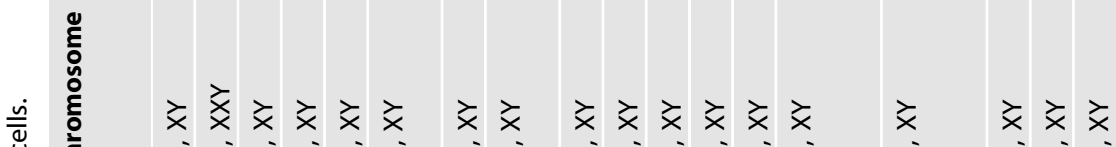

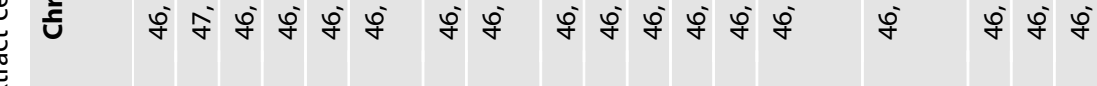

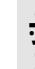

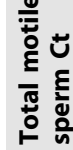

000000

$\circ \circ$

000000

○

$\circ 00$

$\frac{\tilde{y}}{\tilde{n}}$

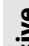

产

000000

$\circ \circ$

000000

○

$\circ 00$

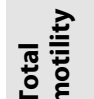

000000

$\circ \circ$

000000

$\circ$

$\circ 00$

$\widehat{\bar{\varepsilon}}$

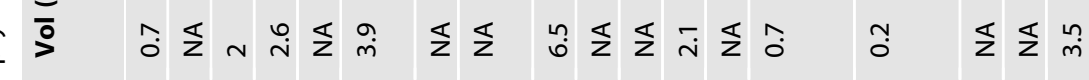

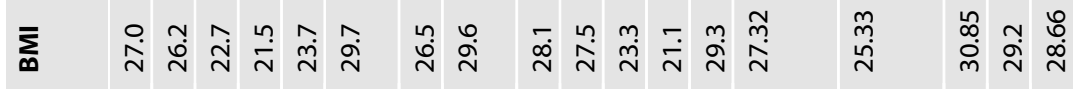

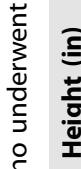

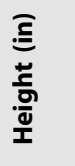

tงละ์ละ

縭

高离

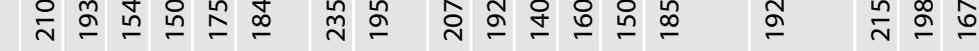

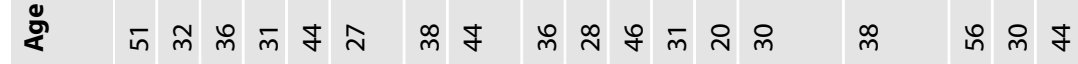

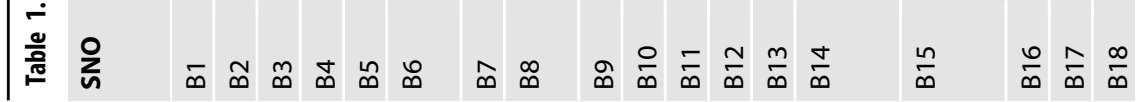


A
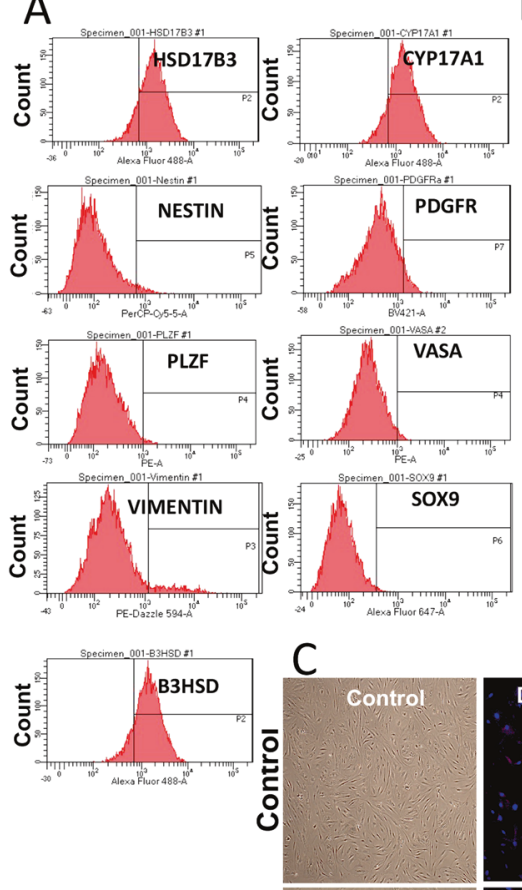

B
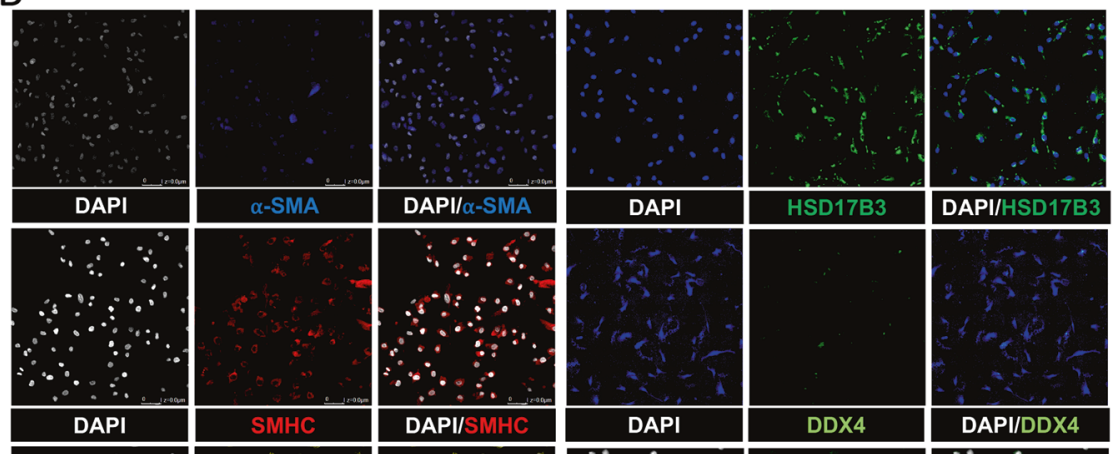

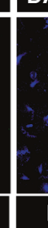
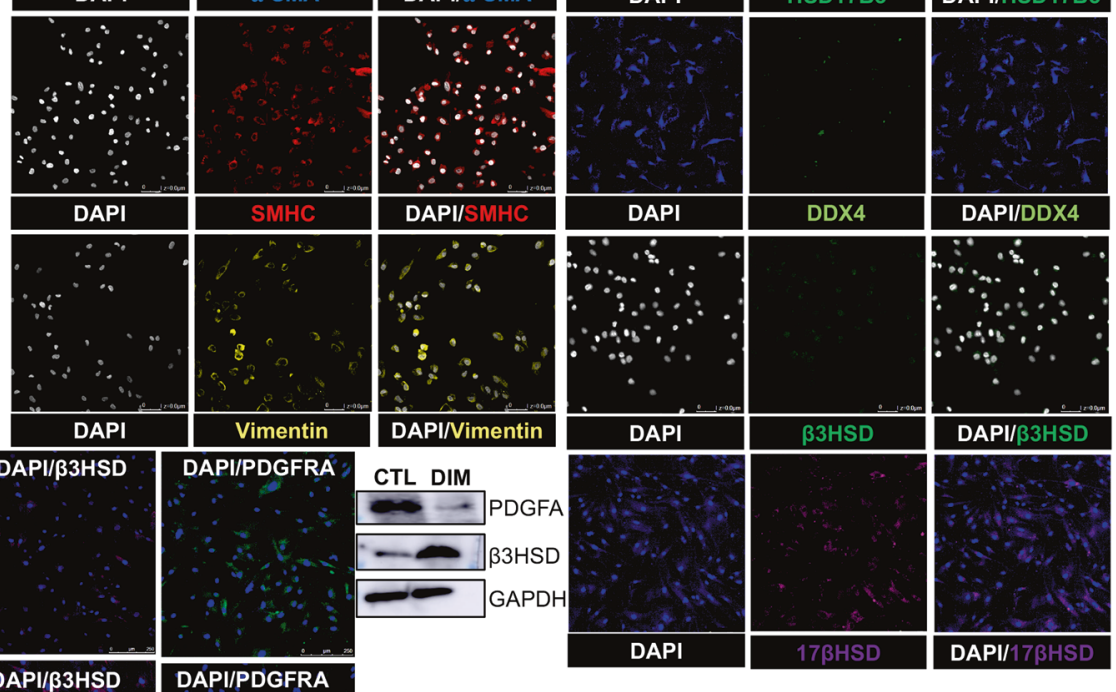

DAPI

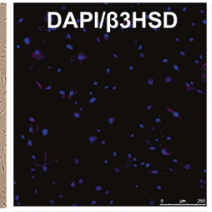

DIM
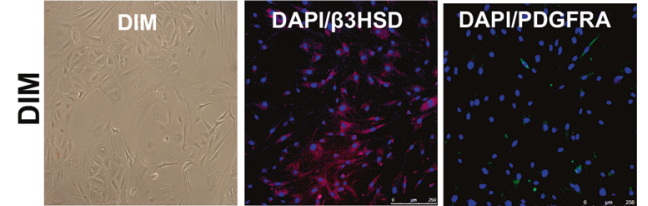

Fig. 1 Characterization of testicular cells. A Flow cytometry results showing the percentage of cell types-Sertoli cells, PMCs, LSCs, ALCs, and germ cells in the TME. B Immunostaining results showing characterization of cell types in the TME at protein levels. C Transformation of LSCs to ALCs in the presence of differentiation-inducing media as indicated by the reduced expression of PDGFR and increased expression of B3HSD.

samples). Together, these results suggested that leptin is upstream of $\mathrm{DHH}$ signaling.

To delineate that leptin augments LSCs through DHH signaling, LSCs were treated with leptin at $1 \mathrm{ng} / \mathrm{ml}$ or $10 \mathrm{ng} / \mathrm{ml}$ alone or in the presence of Vismodigib. Forty-eight hours posttreatment, the expression of alpha SMA, SMHC, Vimentin, and B3HSD was checked at the protein levels. Results showed that expression of alpha SMA was nonsignificantly reduced by $33 \%(p=0.772)$, SMHC by $44.5 \%(p=0.936)$, Vimentin by $40 \%(p=0.489)$, and B3HSD by $38 \%(p=0.498)$ (Fig. 5A-E). Leptin treatment bypassed the inhibitory effects of Vismodigib and induced the expression of alpha SMA by $594 \%(p=0.003)$, SMHC by $467 \%(p=0.001)$, Vimentin nonsignificantly by $106 \%(p=0.100)$, and B3HSD nonsignificantly by $25.2 \%(p=0.789)$ (Fig. 5A-E). Importantly, leptin treatment at a higher concentration $(10 \mathrm{ng} / \mathrm{ml})$, which generally poses an inhibitory effect on LSC differentiation, showed compensatory effects and thus was able to induce the expression of alpha SMA by $806 \%(p=0.0005)$, SMHC by $486 \%(p=0.001)$, Vimentin by $147 \%(p=0.023)$, and B3HSD by $385 \%(p<0.0001)$ (Fig. 5A-E and Sup Fig. 6), suggesting that leptin augments LSC through $\mathrm{DHH}$ signaling.

Furthermore, to evaluate the functional significance of the leptin and $\mathrm{DHH}$ signaling with respect to different cell types in the TME, the Sertoli cells, LSCs, and ALCs were sorted and then treated with $\mathrm{DHH}$ agonist (SAG) and antagonist (Vismodigib), in the presence or absence of increasing doses of leptin for $48 \mathrm{~h}$. Posttreatment, the cells were used to evaluate the impact of leptin-DHH treatments on cell proliferation by MTT assay (Sup Fig. $7 \mathrm{~A}, \mathrm{~B})$. Results delineated that there is minimal to no impact of leptin on cell proliferation upon $\mathrm{DHH}$ agonist (SAG) or antagonist
(Vismodigib) treatment in either cell type (Sup Fig. 7C). Together, the results demonstrate that leptin is upstream of $\mathrm{DHH}$ signaling but does not augment cell proliferation of LSC.

\section{Leptin modulates LSC differentiation to ALCs}

Considering the expression of ALC markers is induced upon leptin, it is likely to module LSC differentiation. To explore this, LSCs were treated with $1 \mathrm{ng} / \mathrm{ml}$ of leptin for 24, 48, 72, and $96 \mathrm{~h}$, followed by flow cytometry analysis (Fig. 6). Results showed a positive shift in the total number of cells staining positive for B3HSD from 0-96 $\mathrm{h}$ (with a $46.5 \%$ nonsignificant increase at $24 \mathrm{~h}(p=0.198), 197 \%$ increase at $48 \mathrm{~h}(p=0.008), 418 \%$ increase at $72 \mathrm{~h}(p=0.108)$, and $341 \%$ increase at $96 \mathrm{~h}(p=0.0006))$ when treated with $1 \mathrm{ng} / \mathrm{ml}$ of leptin, suggesting that leptin increases the differentiation to ALCs at low concentration. For PDGFRa, it was found that leptin treatment induces a negative shift in the total number of cells staining positive for PDGFRa from 0-96h (with a $42.3 \%$ nonsignificant decrease at $24 \mathrm{~h}(p=0.100), 52 \%$ decrease at $48 \mathrm{~h}$ $(p=0.047), 61 \%$ decrease at $72 \mathrm{~h}(p=0.046)$, and $70 \%$ decrease at $96 \mathrm{~h}(p=0.003))$, supporting the previous observation that leptin increases the transformation of LSCs to ALCs. Furthermore, it was found that there is no overall impact $(p>0.05)$ of low doses of leptin treatment on the total number of cells staining positive for SOX9 (with an $8 \%$ nonsignificant increase at $24 \mathrm{~h}(p=0.411), 21 \%$ decrease at $48 \mathrm{~h}(p=0.249), 8 \%$ decrease at $72 \mathrm{~h}(p=0.371)$, and $15 \%$ decrease at $96 \mathrm{~h}(p=0.260))$ and Nestin (with a 7\% increase at $24 \mathrm{~h}(p=0.130), 24 \%$ decrease at $48 \mathrm{~h}(p=0.014), 3.4 \%$ increase at $72 \mathrm{~h}(p=0.244)$, and $2.7 \%$ increase at $96 \mathrm{~h}(p=0.370))$, suggesting that leptin treatment might not have a direct impact on sperm production. 
A

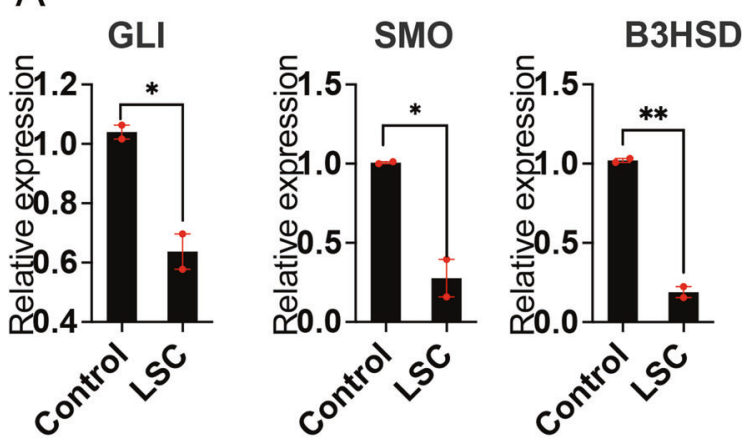

B GLI*

SMO
C

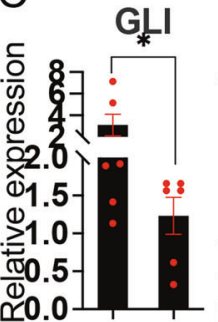

SMO

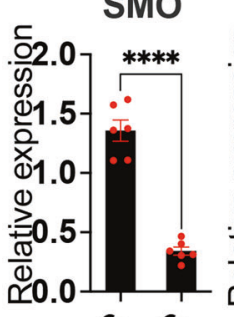

B3HSD

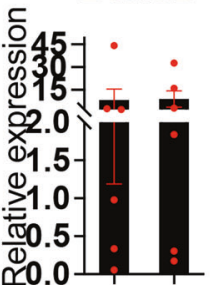

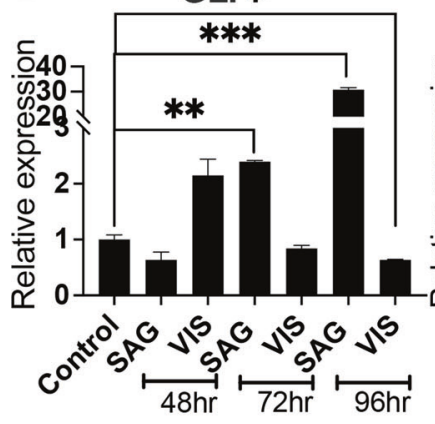
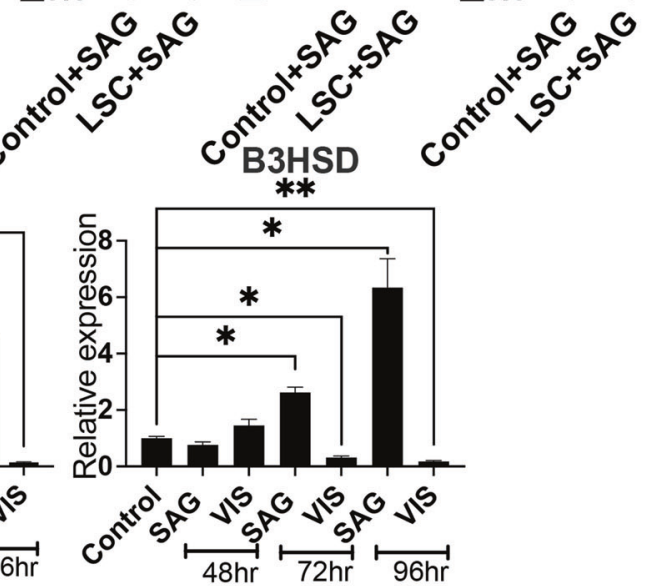

DHH Agonist/Antagonist

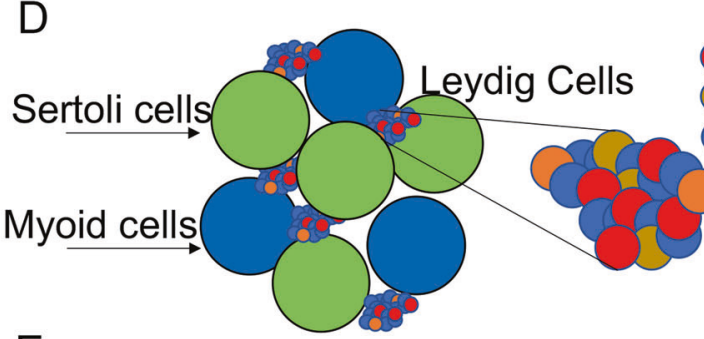

E Total testicular cells
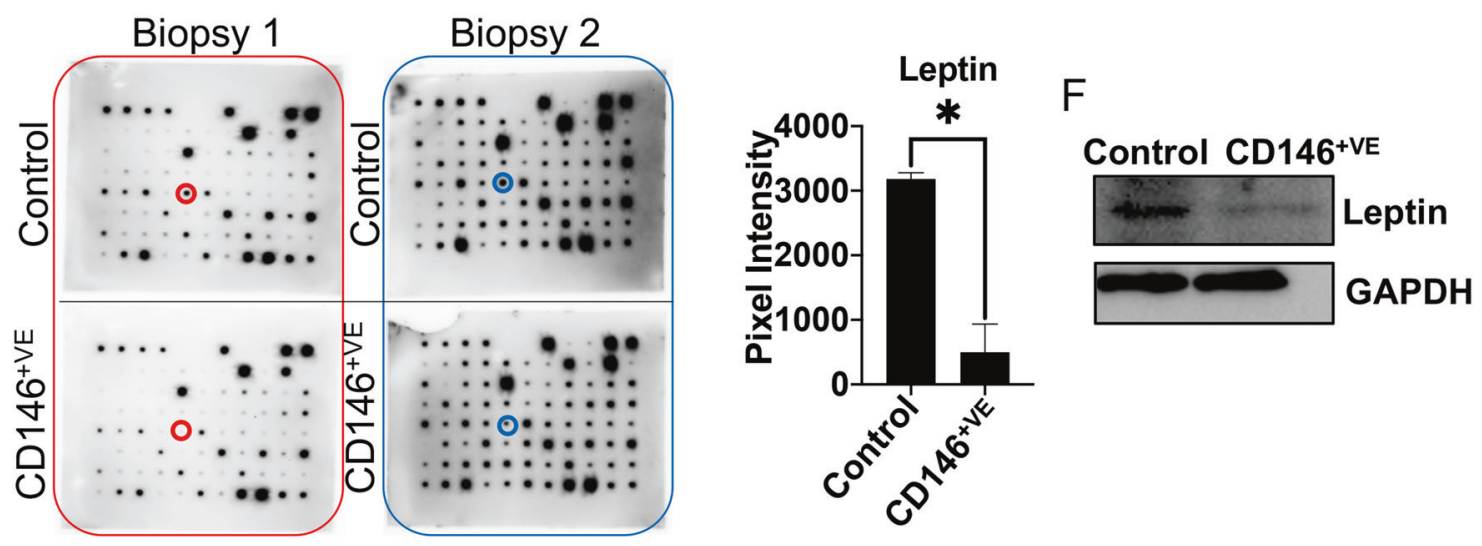

Fig. 2 Role of DHH signaling in differentiation of LSCs. A Comparison of expression of GLI, SMO, and B3HSD in LSCs in the presence (control) or absence (LSC) of the TME (Sertoli and PMCs). B Expression of GLI, SMO, and B3HSD upon DHH agonist and antagonist treatment in LSCs in the presence of the TME in LSCs after 48, 72, and $96 \mathrm{~h}$ of treatment. C Schematic representation of steps taken for evaluating paracrine factors released by the TME to support LSC function. Here green circles represent Sertoli cells, blue-PMCs, small red-ALCs, small brown-SLCs, and small blue-PSLCs. Expression of GLI, SMO, and B3HSD upon DHH antagonist treatment in the presence (control) or absence (CD146 ${ }^{+}$) of the TME in LSCs. D, E Results of cytokine array and F western blot in the presence (control) or absence $\left(\mathrm{CD} 146^{+}\right)$of TME; leptin expression levels in these cells. Asterisks denote $p$ values (e.g., ${ }^{*} p<0.05,{ }^{* * * *} p<0.001$ ).

To further evaluate the role of leptin in modulating LSC differentiation, the leptin receptors (LEPR) were inhibited (using siRNA) before treating the cells with leptin (1 ng/ml), (Sup Fig. 8A). The changes in the population of TME cells were evaluated at 24, 48,72 , and $96 \mathrm{~h}$ using flow cytometry. Results showed that there was no overall impact $(p>0.05)$ of leptin treatment upon LEPR inhibition on the total number of cells staining positive for B3HSD (with a $40.7 \%$ overall increase in cell population $(p=0.434)$ compared to a $13.1 \%$ increase $(p=0.887)$ without leptin treatment), PDGFRa (with a $5.8 \%$ overall decrease in cell 

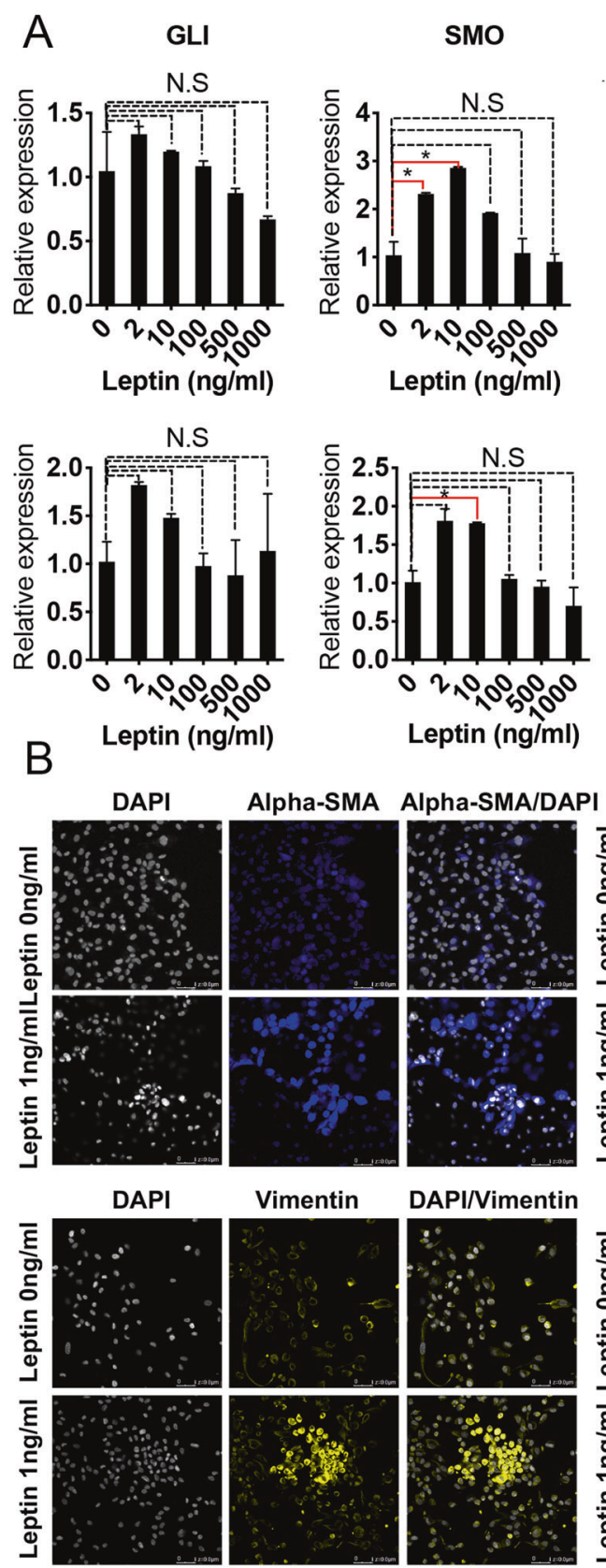

DAPI

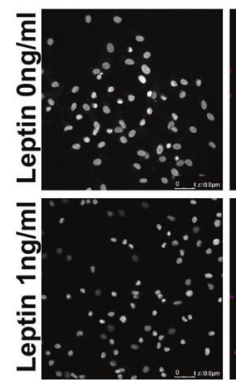

SMO
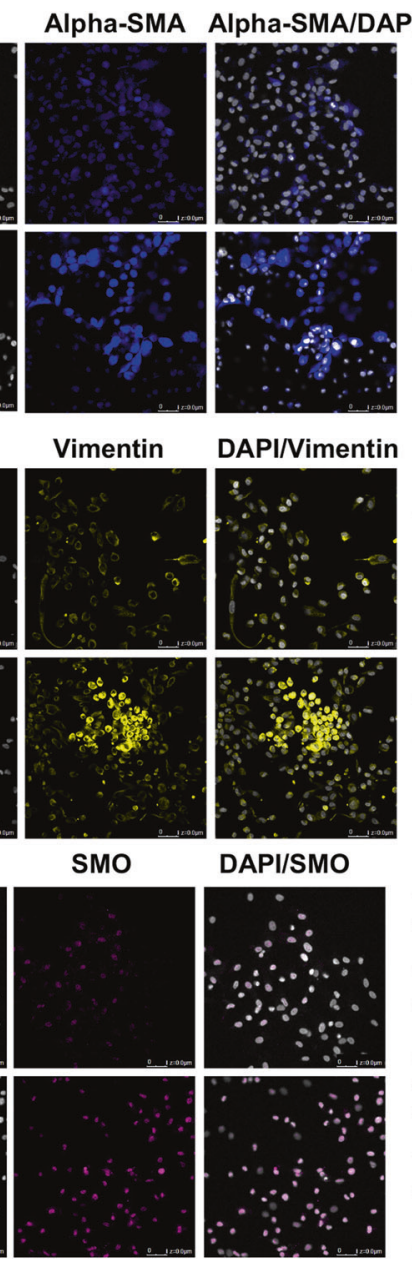

DAPI/Vimentin
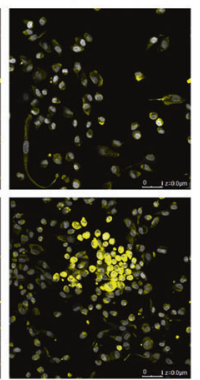

DAPI/SMO

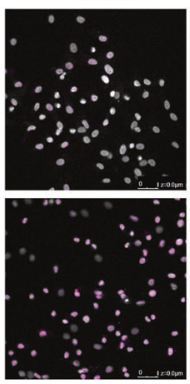

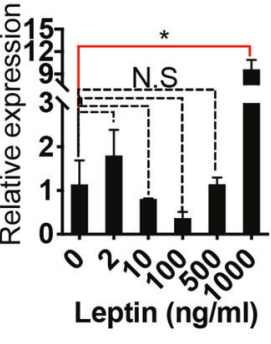

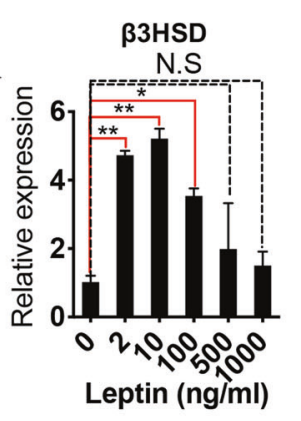

C
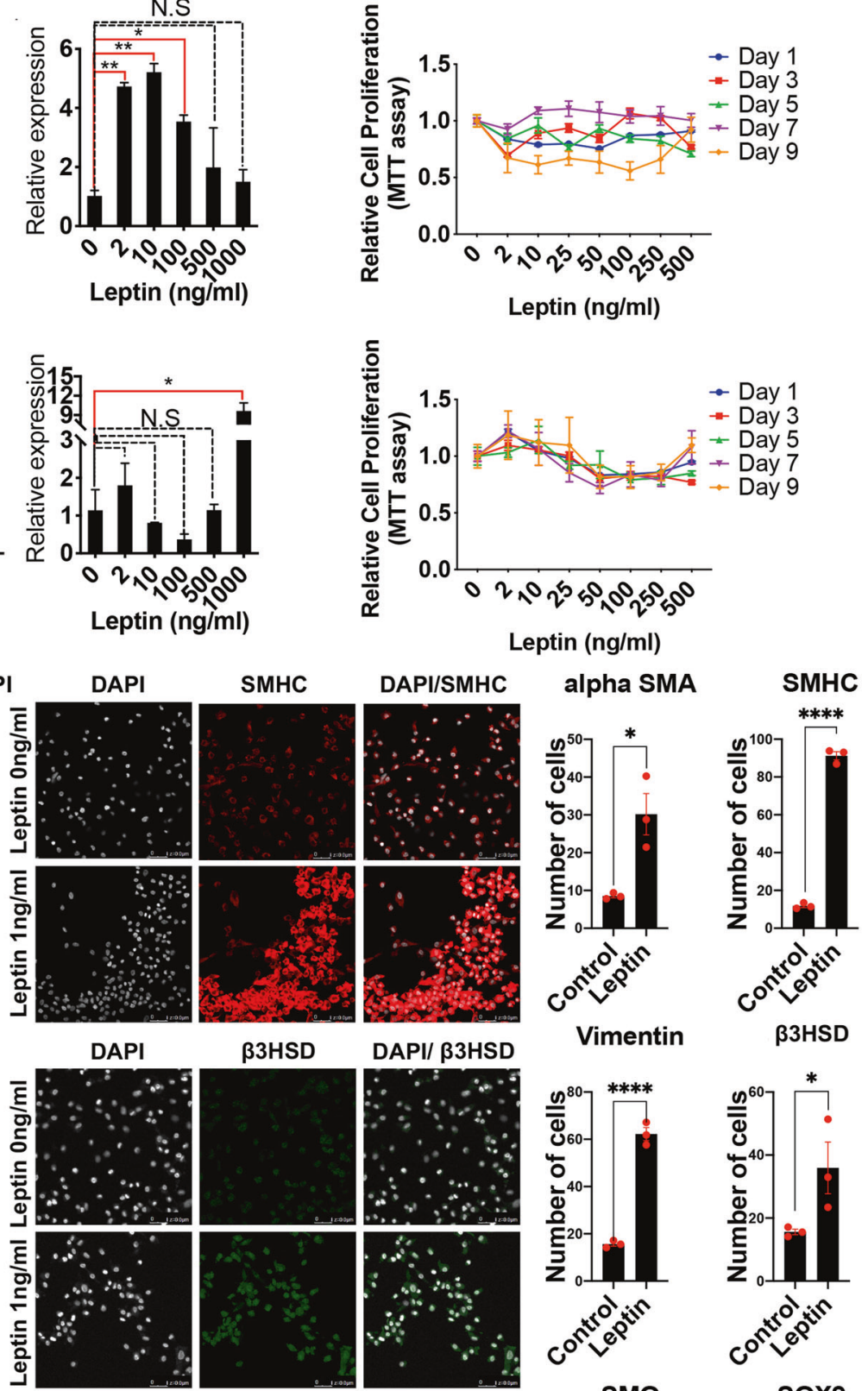

Vimentin

B3HSD
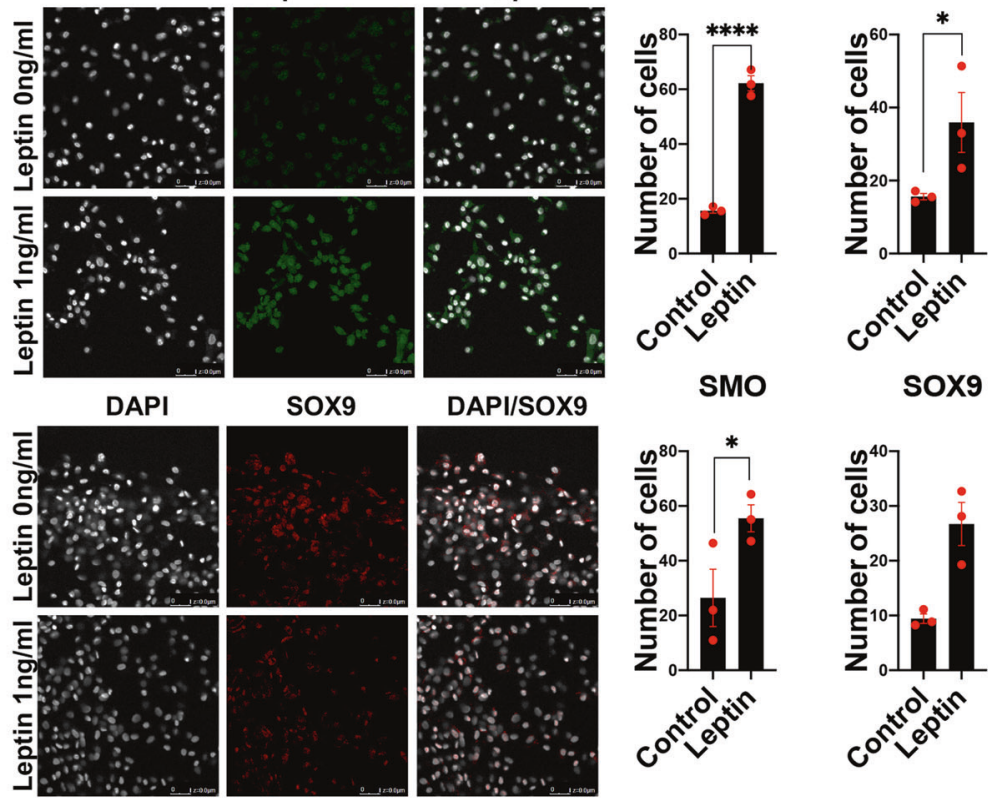

DAPI/SOX9
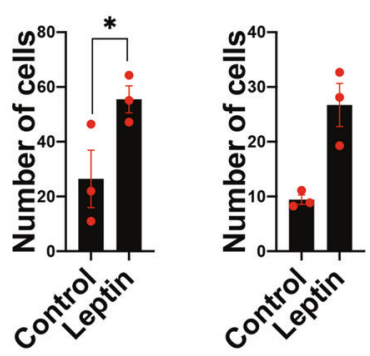

Fig. 3 Studying Paracrine factors released by the TME. A Treatment of cellular composition of the testis (LSCs, ALCs, Sertoli cells, PMCs) with increasing doses of leptin at $0,2,10,100,500$, and $1000 \mathrm{ng} / \mathrm{ml}$, respectively, showing a specific pattern of expression for markers of DHH and LSC differentiation. B Effects of low doses of leptin on protein levels of alpha SMA, SMHC, Vimentin, and B3HSD. C Effects of varying doses of leptin on cell proliferation of cellular composition of the testis. Asterisks denote $p$ values (e.g., ${ }^{*} p<0.05,{ }^{* * *} p<0.001$ ). 


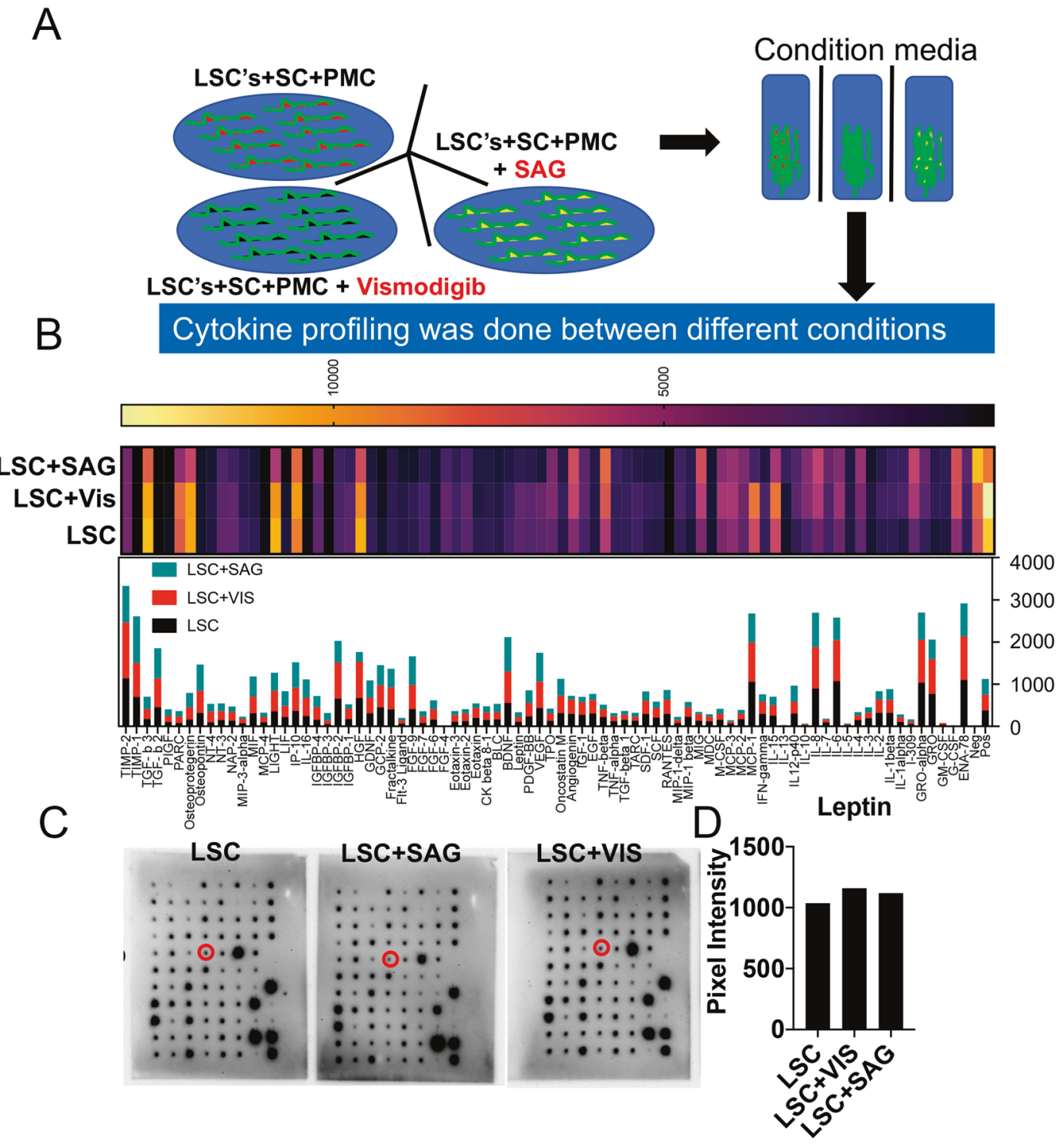

Fig. 4 Leptin is upstream of DHH signaling in TME. Leptin is upstream of DHH signaling in TME. A Schematics of experiment in which LSCs were treated with DHH agonist or antagonist in the presence of the TME, followed by extraction of condition media to perform cytokine antibody array. B Analysis results of the cytokine array between three different conditions (control, DHH agonist treatment, and DHH antagonist treatment). C Blots showing cytokine array with three experimental conditions. D Quantification of Leptin expression levels between the three conditions.

population $(p=0.586)$ compared to a $2.8 \%$ increase $(p=0.606)$ without leptin treatment), SOX9 (with a $34.1 \%$ overall decrease in cell population $(p=0.070)$ compared to a $3.5 \%$ decrease $(p=$ 0.445 ) without leptin treatment), and Nestin (with a $10.9 \%$ overall decrease in cell population $(p=0.13)$ compared to a $0.54 \%$ decrease $(p=0.990)$ without leptin treatment) (Sup Fig. 8B).

To confirm if the impacts of leptin on LSC differentiation are specific, CD146+ cells were sorted and confirmed for the presence of leptin and leptin receptors (Sup Fig. 4A, B). These cells were then exposed to siLEPR ( $25 \mathrm{pmol})$, followed by leptin treatment at $1 \mathrm{l}$ and $10 \mathrm{ng} / \mathrm{ml}$ for 24,48 , and $72 \mathrm{~h}$. Flow cytometry was performed using antibodies against ALCs (B3HSD) (Sup Fig. 9A, B). Results delineated that leptin treatment did not show any impact on the differentiation of LSCs, which were exposed to LEPR inhibition (Sup Fig. 9C) therefore suggesting that the effects of leptin on LSC differentiation are specific. Furthermore, we studied the distribution of LEPR across TME architecture in five random testis biopsies with variable FSH and Testosterone levels. Results showed that LEPR was localized in the interstitium, Leydig cells, mainly in spermatocytes (Sup Fig. 9D).

\section{Enrichment analysis to study leptin-modulated molecular} events

To study the molecular events targeted by leptin to induce changes in LSC function, RNA from LSCs, postexposure to increasing concentrations of leptin were subjected to RNA sequencing. Significantly changed candidates were stratified into four cohorts based on their expression in different leptin concentrations (UUD, UUN, DDU, and DDN, where $U$ represents upregulated, $\mathrm{D}$ represents downregulated, and $\mathrm{N}$ represents no change) (Fig. 7A, B). Protein coding candidates were selected and subjected to (Sup Table 1) hierarchical clustering. Results showed patterns suggesting no hidden subgroups within each comparison (Fig. 7C). Each of these groups were subjected to Ingenuity pathway analysis for enrichment. Results showed that these candidates were directly involved in several important canonical pathways; Leptin Signaling in Obesity, Estrogen Biosynthesis, Androgen Biosynthesis, Sonic Hedgehog Signaling, PDGF Signaling, Human Embryonic Stem Cell Pluripotency, and the pathway for the regulation of several important cytokines like IL-6, IL-8, IL-3, 
A
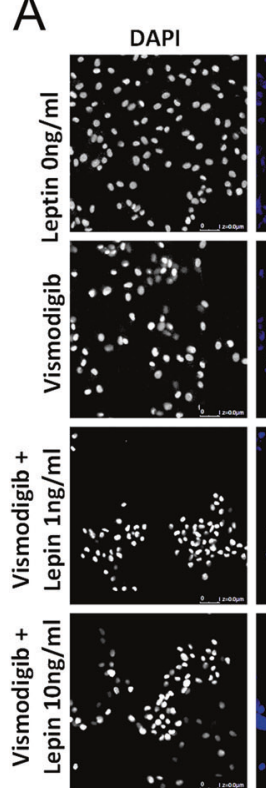

C DAPI
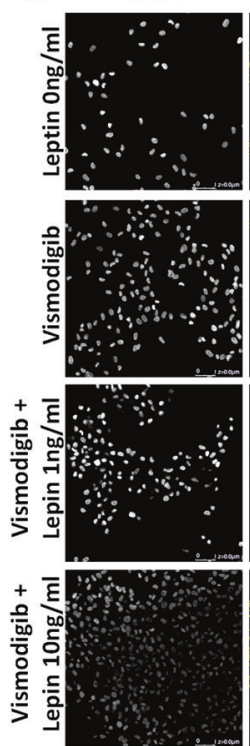
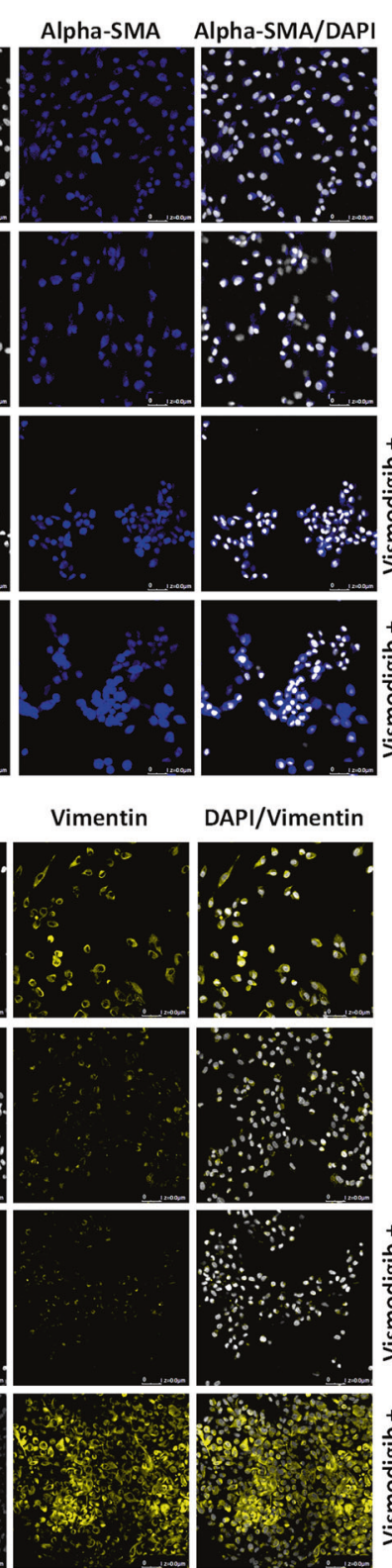
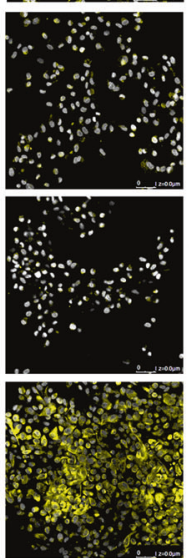

B
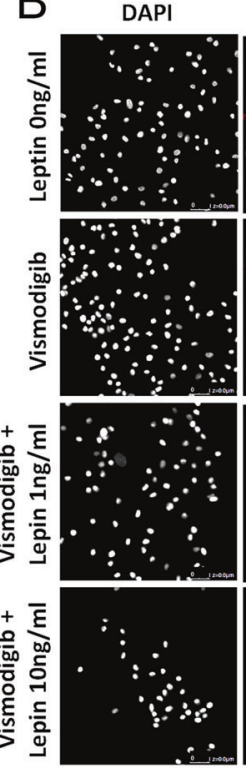

D
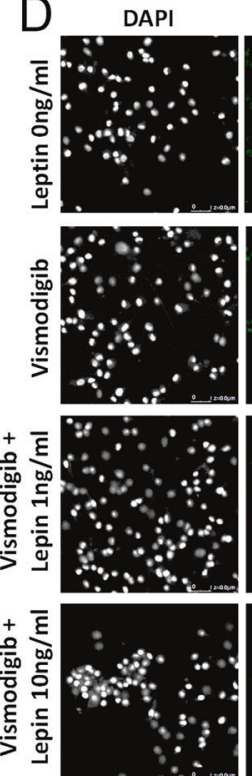

SMHC
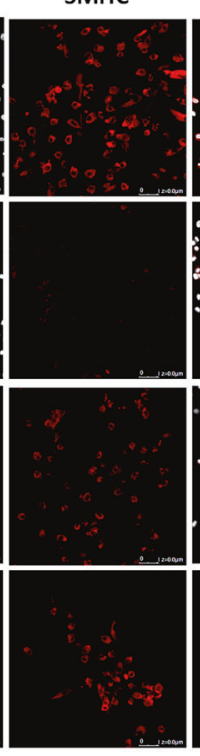

B3HSD
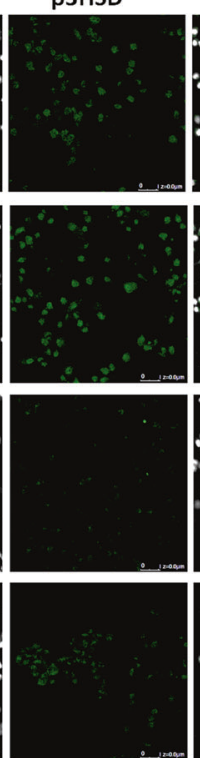

DAPI/SMHC
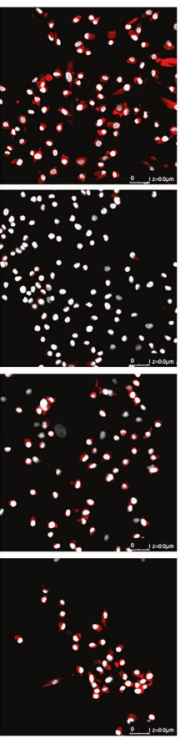

DAPI/B3HSD
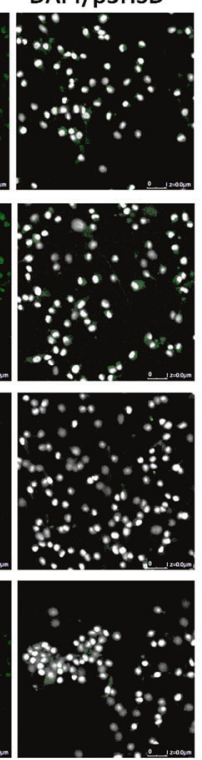

$E$

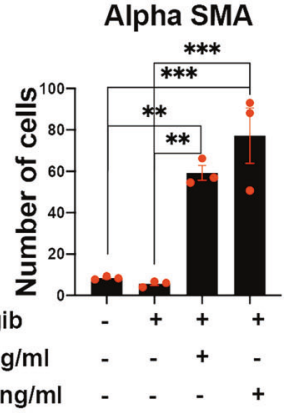

eptin $10 \mathrm{ng} / \mathrm{ml}$

SMHC
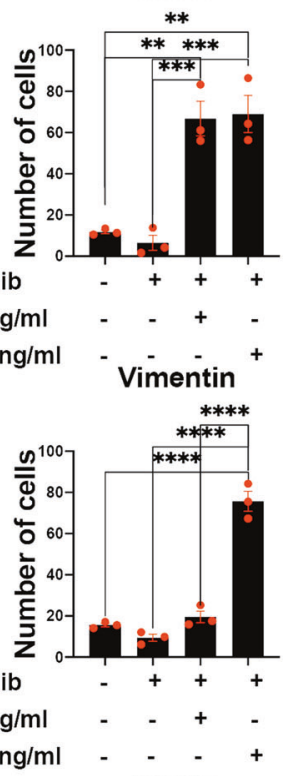

B3HSD

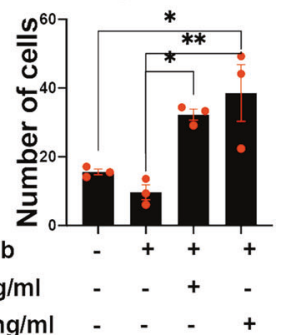

Fig. 5 Leptin influences LSCs through DHH signaling. Leptin augments LSCs through DHH signaling. Cells (LSCs, ALCs, Sertoli cells, PMCs) were treated with Vismodigib (DHH antagonist) in the presence of Leptin (1 or $10 \mathrm{ng} / \mathrm{ml}$ ). Immunostaining showing expression of $\mathbf{A}$ alpha SMA, B SMHC, C Vimentin, and D B3HSD upon post-Vismodigib and leptin treatment. E Quantification of the experimental data to compare the effects of treatment. Asterisks denote $p$ values (e.g., ${ }^{*} p<0.05,{ }^{* * * *} p<0.001$ ).

and IL-15 (Table 2, Sup Table 2, and Sup Figs. 10, 11A). Additionally, to highlight the leptin-induced molecular interactions that could influence $\mathrm{DHH}$ signaling, the candidates from four cohorts were overlaid with DHH signaling genes. Results (Sup Fig. $11 \mathrm{~B})$ revealed important interactions between $\mathrm{DHH}$ signaling and leptin-induced markers.

Furthermore, during the differentiation of LSCs to ALCs, signaling pathways such as DHH, Activin, TGF $\beta$, PDGF, Notch, and WNT signaling plays a key role [24]. Among these, DHH and Activin signaling are known to increase the differentiation of LSCs to ALCs, whereas TGF $\beta$, PDGF, Notch, and WNT signaling pathways are known to potentially induce de-differentiation of ALCs to LSCS $[25,26]$. To study how leptin $(1 \mathrm{ng} / \mathrm{ml})$ could modulate changes through these signaling pathways, we extracted the key markers associated with each of these pathways and studied how (if) leptin treatment altered their expression using RNA sequencing data (Sup Table 3). Results showed that low concentrations of leptin were able to increase the expression of differentiation, inducing $\mathrm{DHH}$ and Activin signaling markers, and reduce the expression of de-differentiation, inducing WNT, TGFb, Notch, and PDGF signaling markers (Sup Table 3 and Sup Fig. 12). Together, the results suggest that leptin is important to modulate molecular events that affect Leydig cell regulation.

\section{DISCUSSION}

Found in the interstitial space of the testis, ALCs are downstream of the HPG regulatory axis [27-29] and are the main source of testosterone production in males [30-32]. LH stimulates testosterone synthesis by $\mathrm{ALCs}$, and the resultant increase in testosterone 

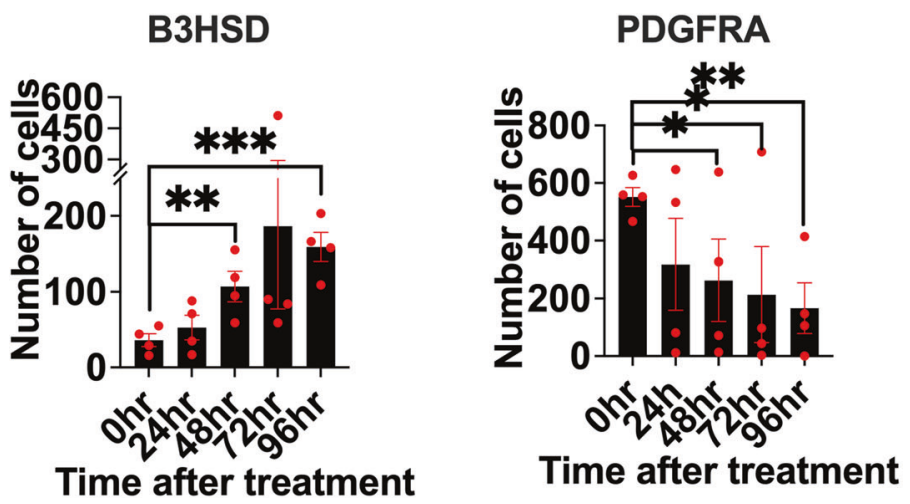

sox9

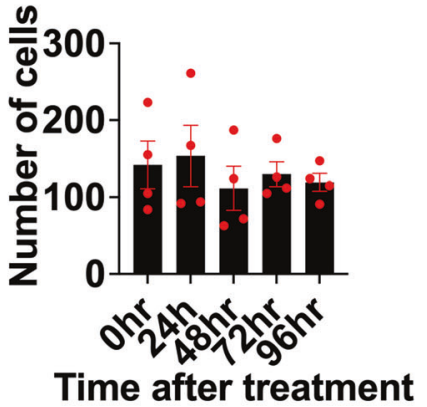

Fig. 6 Leptin regulates LSC differentiation. Flow cytometry analysis showing the effects of increased concentration of leptin ranging from 0 , 1 , and $10 \mathrm{ng} / \mathrm{ml}$ on the percentage of Leydig cells, Sertoli cells, and peritubular myoid cells for $24,48,72$, and $96 \mathrm{~h}$, respectively. Asterisks denote $p$ values (e.g., ${ }^{*} p<0.05,{ }^{* * * *} p<0.001$ ).

exerts negative feedback on the pituitary to decrease LH [27]. In our previous study, we defined the potential of subcutaneously autografting LSCs in combination with the TME (Sertoli and PMCs) to increase serum testosterone without affecting the HPG axis (in murine models). These studies further revealed that $\mathrm{DHH}$ signaling is an essential modulator that is critical for LSC differentiation to the testosterone-producing ALCs in grafts $[16,21]$. Furthermore, autograft survival and testosterone production are impaired in the absence of the TME (Sertoli and PMCs), suggesting the relevance of the TME on LSC function and the understudied role of paracrine factors released from the TME in the regulation of LSCs.

The present study used cells extracted from human testicular biopsies to explore the paracrine factors that could play an instrumental role in regulating LSC differentiation and testosterone production. Results revealed that leptin is the paracrine factor, which is released by the TME and plays an important role in LSC differentiation. Leptin is a $16-\mathrm{kDa}$ protein produced primarily by adipose tissue which exerts a significant influence on reproduction and fertility in mammals [33]. The normal reproductive function requires an adequate amount of leptin that regulates these functions via central (HPG) and testicular steroidogenesis [34]. Leptin exerts a rapid and dose-dependent inhibition of hCGstimulated testosterone production in primary cultures of rat Leydig cells [35]. This effect of leptin is associated with the attenuation of androstenedione levels and an increased level of the precursor molecules progesterone, $17-\mathrm{OH}$ progesterone, and pregnenolone [35]. Moreover, leptin reduces the expression of key elements of the steroidogenic machinery such as SF-1, StAR, and P450scc [36]. Germ cells may exert paracrine control of human Leydig cell steroidogenesis via leptin secretion [37]. At the hypothalamic and pituitary levels, leptin increases $\mathrm{GnRH}$, LH, and FSH production, which leads to a downstream increase in serum testosterone levels [38, 39]. At the level of the testes, leptin decreases testosterone secretion by directly inhibiting testosterone synthesis via mechanisms including downregulation of STAT transcriptional activity and interfering with CAMP signaling [39]. Conversely, testosterone is also important for leptin regulation, and it can inhibit leptin secretion by acting on white adipose tissue [39]. In infertile men with obstructive azoospermia, Sertoli cell-only syndrome, and varicocele, leptin receptor expression in Leydig cells is inversely correlated with the serum levels of testosterone. Thus, overexpression of the leptin receptor by Leydig cells appears to inhibit testosterone production in infertile men [37], suggesting that signaling transduction pathway(s) downstream of leptin exert negative control over steroidogenesis by human Leydig cells. This may explain why low levels of leptin treatment were able to increase LSC differentiation and testosterone levels in cells extracted from the testis biopsies of azoospermia men in our study.

Knowledge regarding the intracellular signaling pathways that control the development of different populations of human
Leydig cells is still incomplete [40]. This study is the first to (1) use cells from human testicular biopsies to study paracrine factors critical for LSCs; (2) identify leptin as a paracrine factor and demonstrated its functional significance on LSC function and differentiation; (3) established the molecular events behind leptinmediated LSC function and differentiation. However, the study is limited by: (1) not exploring if LSCs from men with low testosterone behave differently from men with normal testosterone, not accounting for leptin resistance and its implications on testosterone production; (2) using a method of estimating testosterone (radioimmunoassay) that has been reported to have a cross-reactivity which induces (up to a certain extent) nonspecificity compared to other methods of testosterone estimation such as liquid chromatography/tandem mass spectrometry (LCMS/MS) [41]; (3) lacking a Sertoli-Sertoli tight junction in in vitro condition $[42,43]$, which impacted the immunostaining of Sertoli cell marker Vimentin in comparison to in situ human testis, and (4) using biological replicates (testis biopsies) that are each different from one another in terms of testicular phenotype. In future studies, these limitations will be ameliorated to define leptin as a potential new niche-based therapy for testosterone deficiency.

In conclusion, the results from this study demonstrated the instrumental role of leptin as a paracrine factor secreted by the TME on human LSC function and differentiation. Several aspects of human Leydig cell physiology require further investigation to improve our understanding of the molecular mechanisms through which human reproduction and fertility are regulated.

\section{METHODS}

\section{Human sample}

A total of 18 testis biopsies from men undergoing sperm retrieval (microTESE) were obtained. The IRB protocol was approved by the University of Miami Miller School of Medicine, Miami, FL (protocol no. 20150740). A majority of these men were azoospermic, with average (avg) serum testosterone levels of $474.33 \mathrm{ng} / \mathrm{dL}$, avg LH levels of $7.87 \mathrm{mlU} / \mathrm{ml}$, avg FSH levels of $18.3 \mathrm{mlU} / \mathrm{ml}$, avg body weight of $180.38 \mathrm{lbs}$, avg BMl of 25.86 , and avg age of 35 years. The complete details of the patients can be found in Table 1. The protocol for LSC isolation has been described previously [12]. Briefly, interstitial cells from the testes were dissociated from the seminiferous tubules by treatment with $1 \mathrm{mg} / \mathrm{ml}$ trypsin followed by collagenase (collagenase D; Roche Molecular Biochemicals) treatment in DMEM for up to $1 \mathrm{~h}$ at $34^{\circ} \mathrm{C}$ with shaking. The separated cells were filtered through two layers of $70-\mu \mathrm{m}$ pore-size nylon mesh, centrifuged at $250 \times g$, and resuspended in DMEM. The cells were washed with PBS, centrifuged at $250 \times 9$, resuspended in phenol red-free 1:1 DMEM: F12, and plated for cell culture.

\section{Expansion and characterization of cells}

LSCs from all 13 testis biopsies were cultured in an expansion medium (EM) adapted for embryonic stem cell culture with little modification [44]. LSCs were maintained in this medium for at least 14 days. To induce 

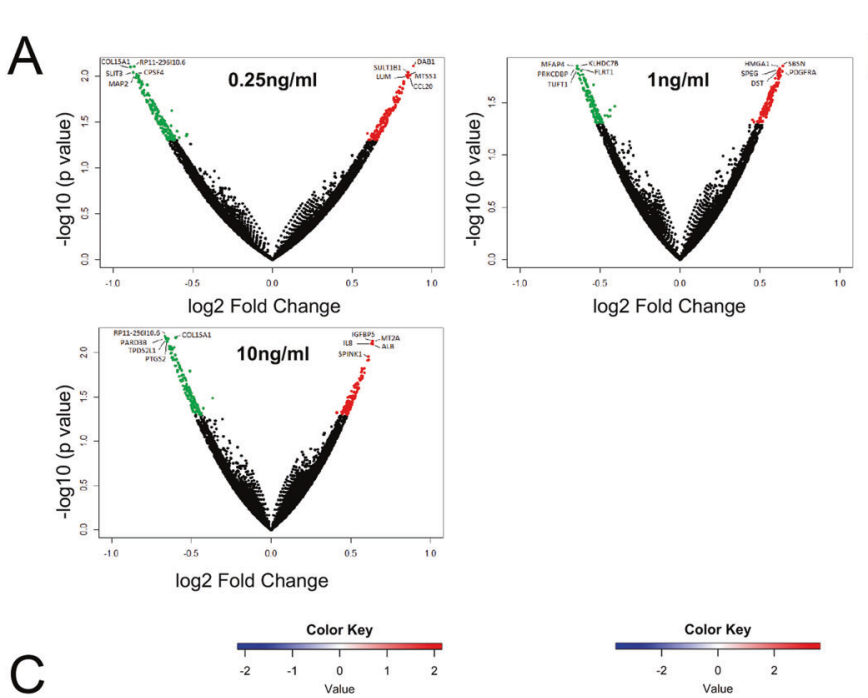

log2 Fold Change
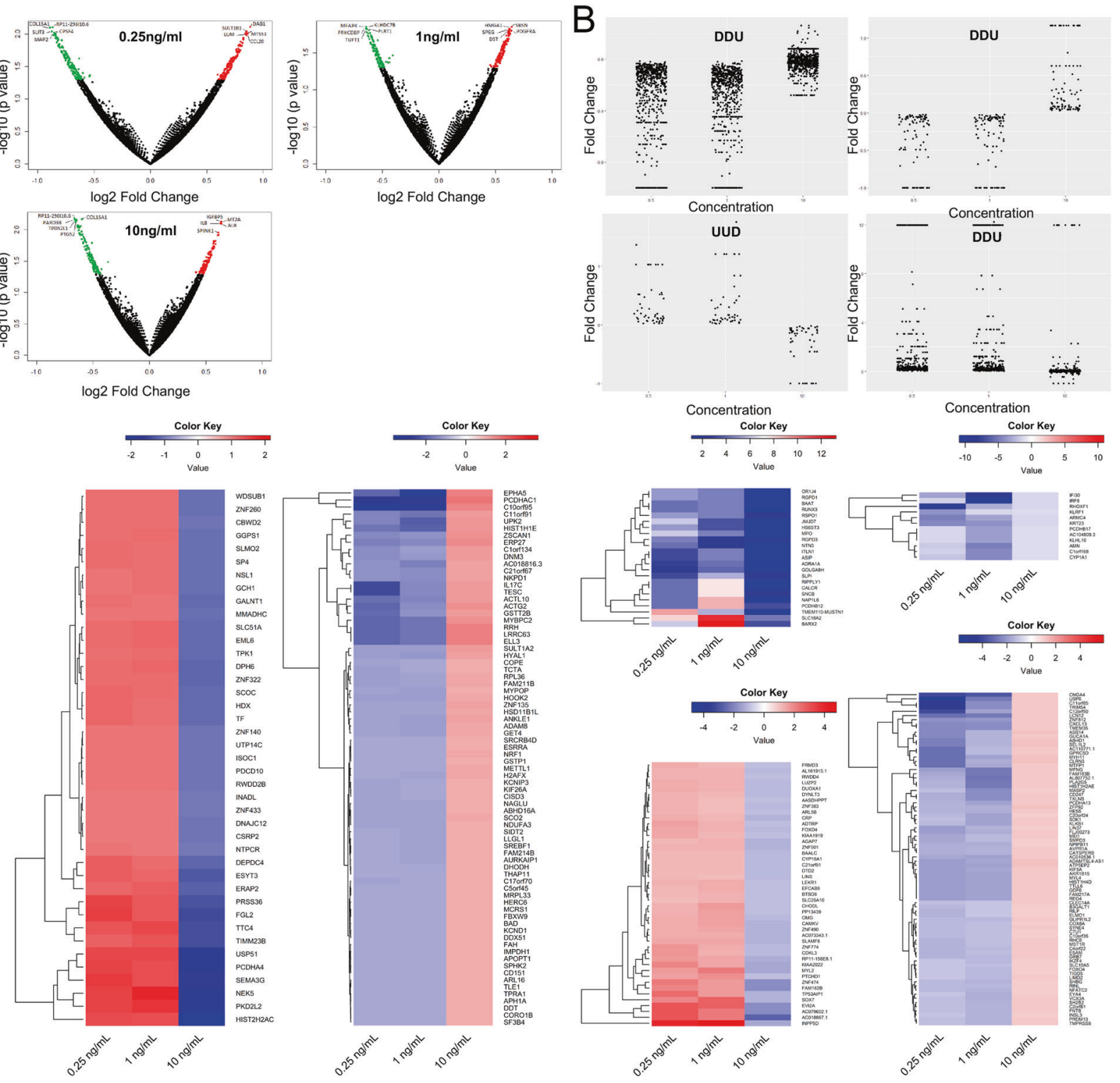

Fig. 7 Leptin-modulated molecular events, an enrichment analysis. Enrichment analysis showing A Volcano plots showing significantly altered candidates upon increasing doses of leptin $(0.25,1$, and $10 \mathrm{ng} / \mathrm{ml})$ with respect to control. Green dots are those genes downregulated in the case sample and red dots are those upregulated in the case sample, with the top five genes in each direction being labeled. B The different cohorts represent the experimental observations UUD, UUN, DDU, and DDN, where U represents upregulated, D represents downregulated, and $\mathrm{N}$ represents no change. Each dot represents an individual gene within each designated pattern, with concentration plotted against fold change. C Heatmaps showing fold change with respect to the control for all patterns in genes across all concentrations. Heatmaps for UUN and DDN are split into two subplots showing the most differential fold change in the two major subgroups of fold change since fold change is not consistently the same across all genes.

differentiation, these cells were replated in a new medium containing differentiation-inducing factors. Differentiation-inducing medium (DIM) included DMEM containing $2 \mathrm{mM}$ L-glutamine and $15 \mathrm{mM}$ HEPES (Thermo Fisher Scientific), 10\% fetal bovine serum (FBS) (Thermo Fisher Scientific), $1 \%$ penicillin/streptomycin (Thermo Fisher Scientific), 2 ng/ml EGF (SigmaAldrich), $1 \mathrm{ng} / \mathrm{ml}$ LIF (Sigma-Aldrich), $10 \mathrm{ng} / \mathrm{ml}$ PDGF-AA (Sigma-Aldrich), $1 \mu \mathrm{M}$ dexamethasone (Sigma-Aldrich), and the insulin transferrin selenium (ITS) supplement (Thermo Fisher Scientific).

\section{Flow cytometry}

Flow cytometry was performed using cells from three independent biopsies. For this, cells were washed with FACS buffer (eBioscience ${ }^{\mathrm{TM}} 00-$ 4222-57) two times. Cells in one tube (unstained) were resuspended in $100 \mathrm{ul} \mathrm{FACS}$ buffer. Cells in the second tube (stained) were fixed with $100 \mathrm{ul}$ of antibody + FACS buffer mix, according to recommended concentrations, and left for $30 \mathrm{~min}$ at $4{ }^{\circ} \mathrm{C}$. Cells in both tubes were again washed two times with FACS buffer and then fixed with BD Cytofix/Cytoperm ${ }^{\mathrm{TM}}$ (Ct No. 554714) Fixation/Permeabilization solution for $20 \mathrm{~min}$ at $4^{\circ} \mathrm{C}$. After washing, cells in the unstained tube were resuspended in $100 \mathrm{ul}$ of perm wash buffer, while conjugating antibodies against PDGFRa, B3HSD, SOX9, Nestin, Vimentin, and PLZF were added to the stained tube. Cells were incubated for $30 \mathrm{~min}$ at $4{ }^{\circ} \mathrm{C}$ and then washed two times with perm wash buffer. Finally, cells were fixed with 500 ul of $4 \%$ PFA (paraformaldehyde) and stored at $4{ }^{\circ} \mathrm{C}$ before analyzing using FACS.

\section{Immunohistochemistry and fluorescence staining}

For immunohistochemical staining, tissue sections of the graft (both experimental and negative control) were stained with hematoxylin and eosin. A genitourinary pathologist (who was blinded to the samples) independently verified the presence of LCSs under $10 \mathrm{x}$ and $60 \mathrm{x}$ magnification. To confirm the presence of different cell types, fluorescence staining was performed on the three testis biopsies that were used for flow 
Table 2. Canonical pathways with which leptin-induced/suppressed candidates were involved.

\begin{tabular}{|c|c|c|c|c|c|}
\hline $\begin{array}{l}\text { Ingenuity canonical } \\
\text { pathways }\end{array}$ & $-\log (p$ value $)$ & Ratio & $\begin{array}{l}\text { Overlaps with } \\
\text { dataset }\end{array}$ & $\begin{array}{l}\text { No overlap with } \\
\text { dataset }\end{array}$ & Molecules \\
\hline Androgen biosynthesis & 1.36 & 0.214 & $3 / 14(21 \%)$ & $11 / 14(79 \%)$ & AKR1C4,EBP,HSD17B3 \\
\hline Androgen signaling & 0.583 & 0.0735 & $10 / 136(7 \%)$ & $126 / 136(93 \%)$ & $\begin{array}{l}\text { CACNA1E,GTF2E1,MAPK3,POLR2C,POLR2D, } \\
\text { POLR2F,POLR2I,PRKACB,SHBG,SRC }\end{array}$ \\
\hline PDGF signaling & 0.91 & 0.093 & $8 / 86(9 \%)$ & $78 / 86(91 \%)$ & $\begin{array}{l}\text { ERAS,INPP5D,MAPK3,RALA,SPHK1,SPHK2,SRC, } \\
\text { TYK2 }\end{array}$ \\
\hline $\begin{array}{l}\text { Human embryonic stem } \\
\text { cell pluripotency }\end{array}$ & 0.595 & 0.0741 & $10 / 135(7 \%)$ & $125 / 135$ (93\%) & $\begin{array}{l}\text { BMP8A,FGFR4,NTRK3,S1PR4,SMAD1,SMAD5, } \\
\text { SPHK1,TCF7L2,TGFB2,WNT6 }\end{array}$ \\
\hline IL-15 production & 1.04 & 0.0909 & $11 / 121(9 \%)$ & $110 / 121$ (91\%) & $\begin{array}{l}\text { CSK,DDR1,EPHA5,EPHB3,ERBB2,FGFR4,MST1R, } \\
\text { NTRK3,RET,SRC,TYK2 }\end{array}$ \\
\hline IL-6 signaling & 0.362 & 0.064 & $8 / 125(6 \%)$ & $117 / 125$ (94\%) & $\begin{array}{l}\text { ABCB1,CRP,CYP19A1,ERAS,HSPB7,IL37,MAPK3, } \\
\text { RALA }\end{array}$ \\
\hline IL-3 signaling & 0.316 & 0.0633 & $5 / 79(6 \%)$ & $74 / 79(94 \%)$ & BAD,ERAS,INPP5D,MAPK3,RALA \\
\hline IL-4 signaling & 0.261 & 0.0588 & $5 / 85(6 \%)$ & $80 / 85(94 \%)$ & ERAS,INPP5D,NFATC2,RALA,TYK2 \\
\hline IL-10 signaling & 0 & 0.0435 & $3 / 69(4 \%)$ & $66 / 69(96 \%)$ & FCGR2B,IL37,TYK2 \\
\hline IL-17 signaling & 0 & 0.05 & $4 / 80(5 \%)$ & $76 / 80(95 \%)$ & CRP,ERAS,MAPK3,RALA \\
\hline IL-15 signaling & 0 & 0.0563 & $4 / 71(6 \%)$ & $67 / 71(94 \%)$ & ERAS,MAPK3,RALA,TYK2 \\
\hline IL-1 signaling & 0 & 0.0549 & $5 / 91(5 \%)$ & $86 / 91(95 \%)$ & ADCY2,ADCY8,IRAK4,MYD88,PRKACB \\
\hline IL-2 signaling & 0 & 0.0492 & $3 / 61(5 \%)$ & $58 / 61(95 \%)$ & ERAS,MAPK3,RALA \\
\hline IL-7 signaling pathway & 0 & 0.0513 & $4 / 78(5 \%)$ & $74 / 78(95 \%)$ & BAD,FOXO4,FOXO6,MAPK3 \\
\hline
\end{tabular}

cytometry using (1) antibody against B3HSD (sc-30820) followed by Alexa Fluor 488 dye (Thermo Fisher Scientific); (2) anti-alpha SMA antibody (AB5694) followed by Alexa Fluor 488 dye; (6) anti-smooth muscle Myosin heavy chain $11 \mathrm{mAb}$ (SMHC11) followed by Alexa Fluor 568 dye; (7) antiVimentin mAb (ab45939) followed by Alexa Fluor 568 dye. All samples were assessed under a fluorescence microscope (Leica Microsystem, Wetzlar, Germany) at 60x. Images were acquired using MetaMorph version 4.6 (Molecular Devices, Sunnyvale, CA, USA) (information on antibodies can be found in Resource Table).

\section{Assay of testosterone concentration}

Condition media was collected from cells (LSCs and CD146 sorted cells) from three random testis biopsies, pre- and posttreatment with either $\mathrm{DHH}$ agonist (SAG), Vismodigib, or leptin in the absence or presence of Vismodigib. All hormone assays were measured at the University of Virginia (UVA) Center for Research and Reproduction Ligand Assay and Analysis Core Laboratory (Charlottesville, VA). Testosterone was measured using a commercially available solid-phase RIA kit (Coat-a-Count Total Testosterone Kit; Siemens Medical Solutions Diagnostics, Tarrytown, NY, USA). Testosterone assay sensitivity $=10 \mathrm{ng} / \mathrm{dl}$; intra-assay coefficient of variation $(C V)=5.0 \%$; inter-assay $C V=8.2 \%$. To avoid variability, an equal number of cells were seeded and were allowed an equal amount of time to expand before extracting the conditioned media for testosterone estimation. Reportable range $=10.0-1600.0 \mathrm{ng} / \mathrm{dL}$; Rodent QC1 $(32.0-60.0 \mathrm{ng} / \mathrm{dL})$, Rodent QC 2 (122-228 ng/dL), Rodent QC 3 (510.0-950.0 ng/dL).

\section{RNA preparation and quantitative real-time PCR}

Total RNA was isolated from cells using the TRlzol method. This was followed by inducing reverse transcription to complementary DNA using
High-Capacity cDNA Reverse Transcription Kits (Applied Biosystems, USA) according to the manufacturer's protocol. The quantitative RT-PCR for indicated genes was performed in TaqMan Universal PCR Master Mix (Applied Biosystems, USA). Quantitation of mRNAs was performed using Applied Biosystems ${ }^{\text {TM }}$ TaqMan $^{\text {TM }}$. Gene expression assays were performed according to the manufacturer's protocol. Samples were analyzed using the BIORAD sequence detection system. All PCRs were performed in triplicate, and the specificity of the reaction was determined by melting curve analysis at the dissociation stage. The relative quantitative method was used for the quantitative analysis. The calibrator was the averaged $\Delta \mathrm{Ct}$ from the untreated cells. The endogenous control was glyceraldehyde 3-phosphate dehydrogenase (GAPDH). All the experiments suggested in section 3 were repeated twice (primer sequences are given in Resource Table).

\section{Cytokine antibody array}

Condition media was extracted from LSCs from two random testis biopsies in the presence of absence (CD146 ${ }^{+\mathrm{ve}}$ ) of the TME, with cells treated with DHH agonist (SAG) or antagonist (Vismodigib) etc. After quantification using Bradford assay, $4 \mathrm{mg} / \mathrm{ml}$ protein were screened using RayBio Human Antibody Array C Series 1000 (RayBiotech, Norcross, GA, USA) according to the manufacturer's instructions. The blots were analyzed using ImageJ software (National Institutes of Health, Bethesda, MD, USA). A total of 80 molecules were selected for detection: Positive control, Negative control, ENA-78 (CXCL5), G-CSF, GM-CSF, GRO a/b/g, GRO alpha (CXCL1), I-309 (CCL1), IL-1 alpha (IL-1 F1), IL-1 -beta (IL-1 F2), IL-2, IL-3, IL-4, IL-5, IL-6, IL-7, IL-8 (CXCL8), IL-10, IL-12 p40/p70, IL-13, IL-15, IFN-gamma, MCP-1 (CCL2), MCP-2(CCL8), MCP-3 (CCL7), M-CSF, MDC (CCL22), MIG (CXCL9), MIP-1 beta (CCL4), MIP-1 delta, RANTES (CCL5), SCF, SDF-1 alpha, TARC (CCL17), TGF 
beta 1, TNF alpha, TNF beta (TNFSF1B), EGF, IGF-1, Angiogenin, OSM, TPO, VEGF-A, PDGF-BB, Leptin, BDNF, BLC (CXCL13), Ck beta 8-1 (CCL23), Eotaxin-1 (CCL11), Eotaxin-2 (CCL24), Eotaxin-3 (CCL26), FGF-4, FGF-6, FGF7 (KGF), FGF-9, FLT-3 Ligand, Fractalkine (CX3CL1), GCP-2 (CXCL6), GDNF, HGF, IGFBP-1, IGFBP-2, IGFBP-3, IGFBP-4, IL-16, IP-10 (CXCL10), LIF, LIGHT (TNFSF14), MCP-4 (CCL13), MIF, MIP-3 alpha, NAP-2 (CXCL7), NT-3, NT-4, OPN (SPP1), OPG (TNFRSF11), PARC, PLGF, TGF beta 2, TGF beta 3, TIMP-1, TIMP-2, and Positive control.

\section{Cell proliferation assay}

Cells from three random testis biopsies were seeded in 96-well plate in quadruplets and were treated with varying doses of leptin (Sigma-Aldrich) ranging from $2,10,25,50,100,250$, and $500 \mathrm{ng} / \mathrm{ml}$. MTT (3-(4,5dimethylthiazole)-2,5-diphenyltetrazolium bromide) assay reagents (EMD Millipore) were added, and the absorbance was measured at $562 \mathrm{~nm}$ after $0,3,5,7$, and 9 days, following standard protocol. All the experiments suggested in section 4 were repeated twice.

\section{RNA sequencing}

FastQ files were put through the FastQC program to check for the quality of reads. Acceptable reads were then put through the adapter trimming software TrimGalore, which runs off the cutadaptpython package. Reads were then aligned against the hg19 genome with the STAR RNAseq aligner and quantified against the GENCODE v19 database at the same time. Postalignment QC stats were run through PicardTools to check for ribosomal contented transcriptome alignment percentages. After alignment, differential expression comparisons were made with the DESeq2 $\mathrm{R}$ package. Due to the lack of replicates, results from this comparison included nominal $p$ value significance instead of FDR corrected $p$ values, as well as normalized expression values. The normalized expression values were then put through a custom pipeline to determine patterns. First, minimum, maximum, and mean values were calculated from the four separate samples for each gene. Then, a standard deviation was calculated across the samples.

Using $0.75 \mathrm{X}$ standard deviation, a range was formed using a maximum value of the baseline concentration expression value $+0.75 \mathrm{X}$ standard deviation and a minimum value of the baseline concentration expression value $-0.75 \mathrm{X}$ standard deviation. Different standard deviations were tested to check different specificity and sensitivity levels and $0.75 \mathrm{X}$ was determined to give the most viable results. Samples were then lined up according to concentration from 0 to 2 . Comparisons to the baseline concentration classifications were then calculated based on comparing the expression value to the calculated range of values. Those that were greater than the max range value were determined to be an upward change of expression in a given sample, and those that were less than the min range value were determined to be a downregulation expression change in a given sample. Based on these patterns of change, we then calculated the patterns that were of most interest. Ingenuity pathway analysis (QIAGEN) was used to enrich the selected markers from each section with respect to their involvement in molecular signaling networks.

\section{Statistical analysis and sample size calculation}

GraphPad Prism (GraphPad Software) was used for statistical analysis. All data were presented as the means \pm SEM. The statistical significance between the two groups was estimated by an unpaired two-tailed $t$-test. Multiple group comparisons were performed using a one-way analysis of variance with the least significant difference test. In all cases, $p<0.05$ was considered statistically significant.

\section{DATA AVAILABILITY}

All data needed to evaluate the conclusions in the paper are present in the paper. Additional data related to this paper may be requested from the corresponding author.

\section{REFERENCES}

1. Kumar P, Kumar N, Thakur DS, Patidar A. Male hypogonadism: symptoms and treatment. J Adv Pharm Technol Res. 2010;1:297-301.

2. Lee DM, O'Neill TW, Pye SR, Silman AJ, Finn JD, Pendleton N, et al. The European Male Ageing Study (EMAS): design, methods and recruitment. Int J Androl. 2009;32:11-24.

3. Afiadata A, Ellsworth P. Testosterone replacement therapy: who to evaluate, what to use, how to follow, and who is at risk? Hosp Pr. 2014;42:69-82.
4. McLachlan RI, O'Donnell L, Meachem SJ, Stanton PG, de K, Pratis K, et al. Hormonal regulation of spermatogenesis in primates and man: insights for development of the male hormonal contraceptive. J Androl. 2002;23:149-62.

5. Spaliviero JA, Jimenez $M$, Allan CM, Handelsman DJ. Luteinizing hormone receptor-mediated effects on initiation of spermatogenesis in gonadotropindeficient (hpg) mice are replicated by testosterone. Biol Reprod. 2004;70:32-38.

6. Tuttelmann F, Damm OS, Luetjens CM, Baldi M, Zitzmann M, Kliesch S, et al. Intratesticular testosterone is increased in men with Klinefelter syndrome and may not be released into the bloodstream owing to altered testicular vascularization- a preliminary report. Andrology. 2014;2:275-81.

7. Li H, Benoit K, Wang W, Motsko S. Association between use of exogenous testosterone therapy and risk of venous thrombotic events among exogenous testosterone treated and untreated men with hypogonadism. J Urol 2016;195:1065-72.

8. Nudleman E, Witmer MT, Kiss S, Williams GA, Wolfe JD. Central serous chorioretinopathy in patients receiving exogenous testosterone therapy. Retina. 2014;34:2128-32.

9. Zang ZJ, Wang J, Chen Z, Zhang Y, Gao Y, Su Z, et al. Transplantation of CD51(+) stem Leydig cells: a new strategy for the treatment of testosterone deficiency. Stem Cells. 2017;35:1222-32.

10. Mendis-Handagama SM, Ariyaratne HB. Differentiation of the adult Leydig cell population in the postnatal testis. Biol Reprod. 2001;65:660-71.

11. Lo KC, Lei Z, Rao ChV, Beck J, Lamb DJ. De novo testosterone production in luteinizing hormone receptor knockout mice after transplantation of leydig stem cells. Endocrinology. 2004;145:4011-5.

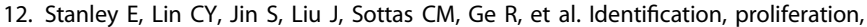
and differentiation of adult Leydig stem cells. Endocrinology. 2012;153:5002-10.

13. Vasta V, Shimizu-Albergine M, Beavo JA. Modulation of Leydig cell function by cyclic nucleotide phosphodiesterase 8A. Proc Natl Acad Sci USA. 2006;103:19925-30.

14. Minegishi T, Kusuda S, Dufau ML. Purification and characterization of Leydig cell luteinizing hormone receptor. J Biol Chem. 1987;262:17138-43.

15. Arora H, Zuttion M, Nahar B, Lamb D, Hare JM, Ramasamy R. Subcutaneous Leydig stem cell autograft: a promising strategy to increase serum testosterone. Stem Cells Transl Med. 2019;8:58-65.

16. Li X, Wang Z, Jiang Z, Guo J, Zhang Y, Li C, et al. Regulation of seminiferous tubule-associated stem Leydig cells in adult rat testes. Proc Natl Acad Sci USA. 2016;113:2666-71.

17. Pyczek J, Buslei R, Schult D, Holsken A, Buchfelder M, Hess I, et al. Hedgehog signaling activation induces stem cell proliferation and hormone release in the adult pituitary gland. Sci Rep. 2016;6:24928.

18. Hooper JE, Scott MP. Communicating with Hedgehogs. Nat Rev Mol Cell Biol. 2005;6:306-17.

19. Machold R, Hayashi S, Rutlin M, Muzumdar MD, Nery S, Corbin JG, et al. Sonic hedgehog is required for progenitor cell maintenance in telencephalic stem cell niches. Neuron. 2003;39:937-50.

20. Shin K, Lee J, Guo N, Kim J, Lim A, Qu L, et al. Hedgehog/Wnt feedback supports regenerative proliferation of epithelial stem cells in bladder. Nature. 2011:472:110-4.

21. Yao HH, Whoriskey W, Capel B. Desert Hedgehog/Patched 1 signaling specifies fetal Leydig cell fate in testis organogenesis. Genes Dev. 2002;16:1433-40.

22. Reissmann T, Felberbaum R, Diedrich K, Engel J, Comaru-Schally AM, Schally AV. Development and applications of luteinizing hormone-releasing hormone antagonists in the treatment of infertility: an overview. Hum Reprod. 1995;10:1974-81.

23. Jiang MH, Cai B, Tuo Y, Wang J, Zang ZJ, Tu X, et al. Characterization of Nestinpositive stem Leydig cells as a potential source for the treatment of testicular Leydig cell dysfunction. Cell Res. 2014;24:1466-85.

24. Ye L, Li X, Li L, Chen H, Ge RS. Insights into the development of the adult Leydig cell lineage from stem Leydig cells. Front Physiol. 2017;8:430.

25. Prince FP. Ultrastructural evidence of mature Leydig cells and Leydig cell regression in the neonatal human testis. Anat Rec. 1990;228:405-17.

26. Sagaradze GD, Basalova NA, Efimenko AY, Tkachuk VA. Mesenchymal stromal cells as critical contributors to tissue regeneration. Front Cell Dev Biol. 2020;8:576176.

27. Neaves WB. Leydig cells. Contraception. 1975;11:571-606.

28. Makabe S, Naguro T, Heyn R, Motta PM. Ultrastructure of human Leydig cells at early gonadal embryogenesis. Ital J Anat Embryol. 1995;100:525-33.

29. Azhar S, Menon KM. Receptor mediated gonadotropin action in gonadal tissues: relationship between blood cholesterol levels and gonadotropin stimulated steroidogenesis in isolated rat Leydig and luteal cells. J Steroid Biochem. 1982;16:175-84.

30. Zhou R, Wu J, Liu B, Jiang $Y$, Chen $W$, Li J, et al. The roles and mechanisms of Leydig cells and myoid cells in regulating spermatogenesis. Cell Mol Life Sci. 2019;76:2681-95. 
31. Pointis G, Latreille MT. Regulation of testosterone production in Leydig cells from fetal mice under dynamic conditions: effect of human chorionic gonadotrophin and 8-bromo-cyclic AMP. J Endocrinol. 1985;107:409-14.

32. Waeber C, Reymond O, Reymond M, Lemarchand-Beraud T. Effects of hyper- and hypoprolactinemia on gonadotropin secretion, rat testicular luteinizing hormone/human chorionic gonadotropin receptors and testosterone production by isolated Leydig cells. Biol Reprod. 1983;28:167-77.

33. Caprio M, Fabbrini E, Isidori AM, Aversa A, Fabbri A. Leptin in reproduction. Trends Endocrinol Metab. 2001;12:65-72.

34. Landry D, Cloutier F, Martin LJ. Implications of leptin in neuroendocrine regulation of male reproduction. Reprod Biol. 2013;13:1-14.

35. Caprio M, Isidori AM, Carta AR, Moretti C, Dufau ML, Fabbri A. Expression of func tional leptin receptors in rodent Leydig cells. Endocrinology. 1999;140:4939-47.

36. Tena-Sempere M, Manna PR, Zhang FP, Pinilla L, Gonzalez LC, Dieguez C, et al Molecular mechanisms of leptin action in adult rat testis: potential targets for leptin-induced inhibition of steroidogenesis and pattern of leptin receptor messenger ribonucleic acid expression. J Endocrinol. 2001;170:413-23.

37. Ishikawa T, Fujioka H, Ishimura T, Takenaka A, Fujisawa M. Expression of leptin and leptin receptor in the testis of fertile and infertile patients. Andrologia. 2007;39:22-27.

38. Tena-Sempere M, Pinilla L, Gonzalez LC, Dieguez C, Casanueva FF, Aguilar E. Leptin inhibits testosterone secretion from adult rat testis in vitro. J Endocrinol. 1999;161:211-8.

39. Zhang J, Gong M. Review of the role of leptin in the regulation of male reproductive function. Andrologia. 2018.

40. Svechnikov K, Landreh L, Weisser J, Izzo G, Colon E, Svechnikova I, et al. Origin development and regulation of human Leydig cells. Horm Res Paediatr. 2010;73:93-101.

41. Handelsman DJ, Jimenez M, Singh GK, Spaliviero J, Desai R, Walters KA. Measurement of testosterone by immunoassays and mass spectrometry in mouse serum, testicular, and ovarian extracts. Endocrinology. 2015;156:400-5.

42. Pelletier RM. The blood-testis barrier: the junctional permeability, the proteins and the lipids. Prog Histochem Cytochem. 2011;46:49-127.

43. Franca LR, Hess RA, Dufour JM, Hofmann MC, Griswold MD. The Sertoli cell: one hundred fifty years of beauty and plasticity. Andrology. 2016;4:189-212.

44. Ge RS, Dong Q, Sottas CM, Papadopoulos V, Zirkin BR, Hardy MP. In search of rat stem Leydig cells: identification, isolation, and lineage-specific development. Proc Natl Acad Sci USA. 2006;103:2719-24.

\section{ACKNOWLEDGEMENTS}

We thank all the mentors (Dr. Dipen J Parekh), collaborators (Dr. Thomas Masterson and Dr. Sanoj Punen), and interns (Meenakshi Manoharan and Khushi Shah) for their insights, suggestions, and support during this study. Additionally, we would like to thank the American Urological Association Research Scholar Award and Stanley Glaser Award to HA.

\section{AUTHOR CONTRIBUTIONS}

$H A, R Q, K K, D S, M P$, and $I C l$ performed the experiments. $H A, D J V B, R Q$, and $R S$ performed the data analysis. $\mathrm{HA}, \mathrm{DL}, \mathrm{JMH}$, and $\mathrm{RR}$ wrote the paper. $\mathrm{HA}$ and RR designed and conceptualized the study.

\section{FUNDING}

This work was supported by American Urological Association Research Scholar Award for HA, Stanley Glaser Award for RR, NIH grants to JMH: 1R01 HL137355, 1R01
HL107110, 1R01 HL134558, 5R01 CA136387, and 5UM1 HL113460, and the Soffer Family Foundation.

\section{COMPETING INTERESTS}

JMH is the Chief Scientific Officer, a compensated consultant, and advisory board member for Longeveron and holds equity in Longeveron, is also the co-inventor of intellectual property licensed to Longeveron, holds equity in Vestion and maintains a compensated professional relationship with Vestion as a consultant and member of the Board of Directors and Scientific Advisory Board, is the co-inventor of intellectual property licensed to Vestion for use in this study, is a scientific co-founder and uncompensated consultant and advisory board member for Heart Genomics and holds equity in Heart Genomics, and is also the co-inventor of intellectual property licensed to Heart Genomics. DJL discloses, she is the secretary-treasurer and executive board member at the American Board of Bioanalysts and American Association of Bioanalysts, is also in the editorial board for the WHO laboratory manual for the examination and processing of human semen Sixth edition and receives travel expenses to board meetings in Geneva, serves on the advisory board of Celmatix Scientific and receives no financial compensation, has equity in the Fellow Health Scientific advisory board, and participates in Roman Health where she receives equity and compensation for Consultation and Advisorship. The authors declare no competing interests.

\section{CONSENT FOR PUBLICATION}

All authors have provided their consent for publication.

\section{ADDITIONAL INFORMATION}

Supplementary information The online version contains supplementary material available at https://doi.org/10.1038/s41419-022-04658-3.

Correspondence and requests for materials should be addressed to Himanshu Arora.

Reprints and permission information is available at http://www.nature.com/ reprints

Publisher's note Springer Nature remains neutral with regard to jurisdictional claims in published maps and institutional affiliations.

(i) Open Access This article is licensed under a Creative Commons Attribution 4.0 International License, which permits use, sharing, adaptation, distribution and reproduction in any medium or format, as long as you give appropriate credit to the original author(s) and the source, provide a link to the Creative Commons license, and indicate if changes were made. The images or other third party material in this article are included in the article's Creative Commons license, unless indicated otherwise in a credit line to the material. If material is not included in the article's Creative Commons license and your intended use is not permitted by statutory regulation or exceeds the permitted use, you will need to obtain permission directly from the copyright holder. To view a copy of this license, visit http://creativecommons. org/licenses/by/4.0/.

(c) The Author(s) 2022 